Engineering Structures (Paper No. ES/04/887/SK)

\title{
SIMPLIFIED INVERSE DYNAMICS MODELS FOR MR FLUID DAMPERS
}

\author{
H.H. Tsang ${ }^{1}$, R.K.L. $\mathrm{Su}^{2}$ and A.M. Chandler ${ }^{3 * *}$ \\ Centre for Earthquake Engineering Research (CEER), \\ Department of Civil Engineering, The University of Hong Kong, \\ Pokfulam Road, Hong Kong, PRC \\ * Corresponding author: Professor A.M. Chandler, CEER, Department of Civil \\ Engineering, The University of Hong Kong, Pokfulam Road, Hong Kong, PRC \\ E-mail: amchandl@hkucc.hku.hk
} Fax: (852) 25595337

Total Number of Pages: 43

Number of Figures: $\quad 15$

Number of Tables: $\quad 6$ 


\section{Abstract}

The magnetorheological (MR) damper is considered to be one of the most promising semi-active control devices for reduction of structural vibration. Due to the damper's nonlinear characteristic, its inverse dynamics model is difficult to obtain. In this paper, a simplified approach, namely the Simplified Inverse Dynamics (SID) model, has been developed for both the Bingham plasticity model and the Bouc-Wen hysteresis model. SID models have then been used to calculate the optimal fluid yield stress or input current, in order to realize the desirable control forces obtained from various optimal control algorithms. For each model, a piston velocity feedback (PVF) algorithm and a damper force feedback (DFF) algorithm have been formulated. The proposed model has been shown to be applicable to both small-scale and large-scale MR dampers. Also, different configurations of MR dampers, such as, different dimension, coil resistance, type of MR fluid, have been employed to show the generic nature of SID model. The effectiveness of force tracking using SID model has been demonstrated through a series of numerical simulations. A multi-storey frame structure with MR damper-brace systems, using a large-scale 20-ton MR damper, has been adopted. Numerical results show that the MR damper with the proposed SID model can produce forces very close to the optimal control forces, and that the response reduction is very close to the case of fully active control. Also, equally high accuracy of force tracking for different shaking levels and frequency contents of ground motions can be observed. The results demonstrate that SID model can be a simple, yet effective, tool for both research and application purposes.

Keywords: magnetorheological (MR) fluid damper; simplified inverse dynamics (SID) model;

semi-active control; piston velocity feedback (PVF) algorithm; damper force feedback (DFF) algorithm; optimal input current 


\section{Introduction}

Semi-active structural control $[1,2]$ has received considerable attention in recent years because it offers the adaptability of active control devices without requiring the associated large power sources, while potentially it also offers the reliability of passive devices. Semi-active control devices are defined as having properties that can be dynamically varied to optimally reduce the responses of a structural system, without increasing the mechanical energy in both the structure and the device. In contrast to fully active systems, semi-active control devices do not have the potential to destabilize the structural system. Examples of such devices include electrorheological (ER) [3, 4] and magnetorheological (MR) fluid dampers [5-7], variable orifice dampers [8], along with variable stiffness devices [9]. Amongst all these dampers, the use of MR fluid dampers is particularly attractive, in terms of simplicity of application, as well as their reliability and robustness.

MR dampers usually consist of a hydraulic cylinder containing micron-sized magnetically polarizable particles suspended within a fluid. The essential characteristic of MR fluids is their ability to reversibly change from free flowing, linear viscous liquids to semi-solids having a controllable yield strength in milliseconds, when exposed to a magnetic field. They are capable of generating large resisting forces, offer highly reliable operation at a modest cost, and require very little power.

In the field of civil engineering, extensive research on MR fluid dampers has been conducted since mid-1990s. The results of various experimental and analytical studies [5, 6] have indicated that these devices are very promising for civil engineering applications. Large-scale MR damper has firstly been developed at the University of Notre Dame (later transferred to the University of Illinois at Urbana-Champaign in 2002) and they demonstrated that these devices are capable of providing the resisting forces required in large-scale structural control applications [10, 11]. Full-scale application was subsequently introduced to structures in 2001 for reducing wind and seismic responses. One successful case is its application in the cable-stayed bridge crossing the Dongting Lake where it meets the Yangtze River in southern central China [12]. A total of 312 MR fluid dampers have been installed on 156 stayed 
cables to suppress wind-rain-induced cable vibration. A comprehensive state-of-the-art literature review of the development of MR fluid dampers in civil engineering application can be found in Ref. [7].

With the input of structural responses, various control algorithms [13] have been developed to achieve the optimal damper forces. As the ideal semi-active device can only produce a dissipative control force, in addition to the intrinsically nonlinear and changeable damping nature of MR dampers, development of control strategies that are practical to implement and that can fully utilize the semi-active capabilities of these devices is particularly important. Examples of such control strategies [14] are the bang-bang controller, the clipped-optimal controller and the Lyanpunov controller.

Chang and Zhou [15] successfully tackled this problem by employing a neural network (NN) emulation of inverse dynamics in the realization of the optimal control force. Recurrent NN models were constructed based on a few previous time steps of displacement, damper force, voltage signal, and the optimal damper force. It was shown to be beneficial and essential to develop an inverse dynamics model to obtain the required input voltage or current for the MR damper to produce forces as close as possible to the optimal ones. Yet, it seems that generally this inverse dynamics model using NN may be too complicated and difficult to implement.

In this study, a simplified approach, namely the Simplified Inverse Dynamics (SID) model, has been developed in Section 2, for both the Bingham plasticity model and the Bouc-Wen hysteresis model. SID models are employed to obtain the optimal input current for the MR fluid damper, in order to emulate the optimal force. For each model, a piston velocity feedback (PVF) algorithm and a damper force feedback (DFF) algorithm have been formulated. The proposed model has been shown to be applicable to both small-scale and large-scale MR dampers. Also, different configurations of MR dampers, such as, different dimension, coil resistance, type of MR fluid, have been employed to show the generic nature of SID model. The effectiveness of force tracking using SID model has been demonstrated through a series of numerical simulations. A multi-storey frame structure with MR damper-brace systems [16], as illustrated in Section 3, excited by 1940 El Centro and 1994 Northridge earthquake ground motions, has been adopted. Linear quadratic regulator (LQR) has been employed to obtain the optimal damper forces, 
which has been introduced in Section 4. Also, accuracy of force tracking for different shaking levels and frequency contents of ground motions has been demonstrated in Section 5.

\section{Simplified Inverse Dynamics (SID) Model}

\subsection{MR Damper Constraints}

The SID model has been designed for semi-active MR fluid dampers, with the purpose of changing their dynamic characteristics in real time to provide a range of dissipative control forces. The optimal control force can be obtained by various control algorithms, such as the Linear Quadratic Regulator (LQR), the Linear Quadratic Gaussian (LQG), the Instantaneous Optimal Prediction Control, and so forth [13]. Basically, there is no restriction on what type of control algorithm should be used. But, there are two intrinsic constraints due to the characteristics of the MR dampers, namely, the passivity constraint and the limitation constraint.

\subsubsection{Passivity Constraint}

In active control, forces can be produced in any of the four quadrants in the force-velocity graph, while semi-active devices can only produce forces in the first and third quadrants (Figure 1a), at which the forces are dissipative, given as $\quad F(t)=\left\{\begin{array}{cll}F_{\text {Optimal }}(t) & ; \quad F_{\text {Optimal }}(t) \cdot v_{0}(t)>0 \\ 0 & ; & F_{\text {Optimal }}(t) \cdot v_{0}(t) \leq 0\end{array}\right.$

where $v_{0}(t)$ is the piston velocity and $F_{\text {Optimal }}(t)$ is the optimal damper force obtained by any chosen control algorithm.

As the actual damper resisting force $F_{\text {Actual }}(t)$ will have the same sign as the piston velocity $v_{0}(t)$ at time $t$, the optimal damper force $F_{\text {Optimal }}(t)$ obtained can be compared with $F_{\text {Actual }}(t)$. Hence, $F_{\text {Optimal }}(t)$ is realizable provided that 


$$
\operatorname{sgn}\left[F_{\text {Optimal }}(t)\right]=\operatorname{sgn}\left[F_{\text {Actual }}(t)\right]
$$

\subsubsection{Limitation Constraint}

In addition to the passivity constraint, there is an upper and lower limit on the force that the MR damper can produce, which is dependent on the motion of the piston, i.e.

$$
\left|F_{\text {min. }}(t)\right| \leq\left|F_{\text {Optimal }}(t)\right| \leq\left|F_{\text {max }}(t)\right|
$$

$\left|F_{\text {max. }}(t)\right|$ and $\left|F_{\text {min. }}(t)\right|$ are, respectively, the magnitude of the maximum and minimum damper forces that can be achieved at time $t$ (Figure $1 \mathrm{~b}$ ), which are controlled by the piston velocity $v_{0}(t)$ at time $t$.

Based on the two constraints above, if $F_{\text {Optimal }}(t)$ is realizable by the MR damper, implying that it satisfies both Equations (2) and (3), the SID model may be employed to obtain the optimal input current or voltage and produce the desirable damper force. Otherwise, the input voltage or current should be set at either zero or the maximum achievable level.

\subsection{Bingham Plasticity Model}

A simple Bingham plasticity model is effective in describing the essential field-dependent fluid characteristic. Phillips [17] derived a quintic equation, which can govern the pressure gradient in the flow of a Bingham fluid. Gavin et al. [3, 4] extended the idea, based on the simple parallel-plate model, for describing the force-velocity behaviour of cylinder ER dampers. Various researchers [16, 18] have successfully employed this simple, yet sufficiently accurate, model to investigate the possibility of using MR dampers for civil engineering applications.

Based on the parallel-plate model further developed by Spencer et al. [10], the total damper force $F$ may be decomposed into a controllable force $F_{\tau}$ due to controllable yield stress $\tau_{0}$ and an uncontrollable force $F_{u c}$. The uncontrollable force includes two parts, a viscous force $F_{\eta}$ and a 
constant friction force $F_{f}$. Therefore, the total damper force may be expressed by Equation (4) and illustrated in Figure 1b.

$$
F=F_{\tau}+F_{\eta}+F_{f}
$$

where $\quad F_{\eta}=\left(1+\frac{w h}{2 A_{p}}\right) \frac{12 \eta L A_{p}}{w h^{3}} A_{p} \cdot v_{0}$

and $\quad F_{\tau}=c \frac{\tau_{0} L A_{p}}{h} \operatorname{sgn}\left(v_{0}\right)$

in which $c \approx 2.07+\frac{1}{1+0.4 T}$ is bounded to the interval [2.07,3.07], and $T$ is defined as

$$
T=\frac{w h^{2} \tau_{0}}{12 A_{p} \eta v_{0}}
$$

Equation (6a) can be rewritten as

$$
F_{\tau}=\left(2.07+\frac{12 A_{p} \eta v_{0}}{12 A_{p} \eta v_{0}+0.4 w h^{2} \tau_{0}}\right) \frac{\tau_{0} L A_{p}}{h} \operatorname{sgn}\left(v_{0}\right)
$$

where $L$ is the effective axial pole length, $A_{p}$ is the cross sectional area of the piston, $w$ is the width of the rectangular plate, $h$ is the gap width between two parallel plates, $\eta$ is the Newtonian viscosity and $\tau_{0}$ is the fluid yield stress.

\subsubsection{Piston Velocity Feedback (PVF) Algorithm}

If $F_{\text {Optimal }}(t)$ is realizable based on the two constraints stated in Section 2.1, then, the optimal fluid yield stress $\tau_{0}(t)$ may be calculated as follows

$$
F_{\eta}(t)=C_{\eta} \cdot v_{0}(t) \quad \text { where } \quad C_{\eta}=\left(1+\frac{w h}{2 A_{p}}\right) \frac{12 \eta L A_{p}}{w h^{3}} A_{p}
$$

and $\quad F_{\tau}(t)=c(t) \frac{\tau_{0}(t) L A_{p}}{h} \operatorname{sgn}\left[v_{0}(t)\right]$

where $\quad c(t)=\left(2.07+\frac{12 A_{p} \eta v_{0}(t)}{12 A_{p} \eta v_{0}(t)+0.4 w h^{2} \tau_{0}(t)}\right)$ 


$$
\approx\left(2.07+\frac{12 A_{p} \eta v_{0}(t)}{12 A_{p} \eta v_{0}(t)+0.4 w h^{2} \tau_{0}(t-\Delta t)}\right) \text { denoted by } \tilde{c}(t)
$$

As the fluid yield stress is expected to vary continuously with time, the approximation of $c(t)$ by $\tilde{c}(t)$ is expected to be sufficiently accurate when $\Delta t \rightarrow 0$.

It is noted that all three components of the damper force always possess the same sign, hence, equating the magnitude of the optimal damper force $\left|F_{\text {Optimal }}(t)\right|$ to the sum of the magnitudes of the three damper force components gives

$$
\begin{gathered}
\left|F_{\text {Optimal }}(t)\right|=\tilde{c}(t) \frac{\tau_{0}(t) L A_{p}}{h}+C_{\eta}\left|v_{0}(t)\right|+F_{f} \\
\text { Rearranging, } \quad \tau_{0}(t)=\left[\left|F_{\text {Optimal }}(t)\right|-C_{\eta}\left|v_{0}(t)\right|-F_{f}\right] \frac{h}{\tilde{c}(t) L A_{p}}
\end{gathered}
$$

The above SID model may be used to obtain the desired $\tau_{0}(t)$, and hence, the optimal damper force $F_{\text {Optimal }}(t)$ may be realized. To achieve this, an extra velocity sensor for the damper is required. However, due to reasons such as cost effectiveness and installation difficulties, the velocity sensor may not be readily available. Hence, a further algorithm has been developed in the next section in order to overcome this limitation.

\subsubsection{Damper Force Feedback (DFF) Algorithm}

Although the damper velocity $v_{0}(t)$ may not be available for feedback, it can be approximated by the measured damper force $F_{\text {Actual }}(t)$. Equating the magnitude of the actual damper force $\left|F_{\text {Actual }}(t)\right|$ to the sum of the magnitudes of the three damper force components gives

$$
\begin{aligned}
\left|F_{\text {Actual }}(t)\right| & =\tilde{c}(t) \frac{\tau_{0}(t-\Delta t) L A_{p}}{h}+C_{\eta}\left|v_{0}(t)\right|+F_{f} \\
& \approx c(t-\Delta t) \frac{\tau_{0}(t-\Delta t) L A_{p}}{h}+C_{\eta}\left|v_{0}(t)\right|+F_{f}
\end{aligned}
$$

It is noted that time-continuity property of $c(t)$ has also been employed in Equation (12b). 
Rearranging, $\quad\left|v_{0}(t)\right|=\frac{1}{C_{\eta}}\left[\left|F_{\text {Actual }}(t)\right|-c(t-\Delta t) \frac{\tau_{0}(t-\Delta t) L A_{p}}{h}-F_{f}\right]$

Substituting Equation (13) into Equation (11), the SID model becomes

$$
\tau_{0}(t)=\tau_{0}(t-1)+\left[\left|F_{\text {Optimal }}(t)\right|-\left|F_{\text {Actual }}(t)\right|\right] \frac{h}{c(t-\Delta t) L A_{p}}
$$

For practical applications, the input parameter for the dampers should be either the voltage or the current. Yang [19] has showed that there are specific relationships between fluid yield stress and current for different configurations of MR fluid dampers, which can be explicitly established. It is observed that the fluid yield stress can be modelled by an exponential function [Equation (15)]. The comparison between the proposed model and the experimental results [19] has been shown in Figures 2(a) and 2(b).

$$
\tau_{0}(t)=k_{1}-k_{2} e^{-k_{3} i(t)} \geq 0
$$

where $k_{1}, k_{2}$ and $k_{3}$ are constants. The modelling accuracy is excellent, especially for larger yield stress, of which the accuracy is more important. Hence, the proposed SID model can provide a simple, generic and efficient tool to obtain the required input current, so as to vary the magnetic field inside the MR damper and hence provide the desired damper force.

\subsection{Bouc-Wen Hysteresis Model}

Although the Bingham plasticity model is useful and easily implemented, it is not sufficient to describe the dynamic behaviour of the MR dampers. Spencer et al. [20] proposed a mechanical model for MR dampers based on the Bouc-Wen hysteresis model [21]. In this model, the total damper force $F$ is given by

$$
F=\alpha z+c_{0}(\dot{x}-\dot{y})+k_{0}(x-y)+k_{1}\left(x-x_{0}\right)=c_{1} \dot{y}+k_{1}\left(x-x_{0}\right)
$$

where $z$ and y are governed by

$$
\dot{z}=-\gamma|\dot{x}-\dot{y}| z|z|^{n-1}-\beta(\dot{x}-\dot{y})|z|^{n}+A(\dot{x}-\dot{y})
$$




$$
\dot{y}=\frac{1}{c_{0}+c_{1}}\left\{\alpha z+c_{0} \dot{x}+k_{0}(x-y)\right\}
$$

in which $x$ is the displacement of the damper; $y$ is the internal pseudo-displacement of the damper; $z$ is the evolutionary variable that portray the hysteretic behaviour of the damper; $k_{1}$ is the accumulator stiffness; $c_{0}$ is the viscous damping at large velocities; $c_{1}$ is the viscous damping for force roll-off at low velocities; $k_{0}$ is the stiffness at large velocities; and $x_{0}$ is the initial displacement of the spring $k_{1} ; \alpha$ is the evolutionary coefficient; and $\beta, \gamma, n$ and $A$ are the shape parameters of the hysteresis loops.

Spencer [22] showed that the upper bound of the evolutionary variable $z$, that is the ultimate hysteretic strength $z_{u}$ is

$$
z_{u}=\left(\frac{A}{\gamma+\beta}\right)^{\frac{1}{n}}
$$

As the stiffness forces of the MR damper are small, for simplicity, they may be neglected as in the following derivation. Substituting Equation (19) into Equation (18) and then into Equation (16), the upper bound of the damper force $F_{u}$ may be simplified as

$$
F_{u}=\frac{c_{1} \alpha z_{u}}{c_{0}+c_{1}} \operatorname{sgn}(\dot{x})+\frac{c_{0} c_{1}}{c_{0}+c_{1}} \dot{x}=F_{\tau}+F_{\eta}
$$

The controllable yield force $F_{\tau}$ due to the controllable yield stress $\tau_{0}$, which in turn is controlled by the input current $i$, is included in the functions of $\alpha, c_{0}$ and $c_{1}$. The viscous force $F_{\eta}$, different from the Bingham model, is also dependent on the input current $i$, which is included in the functions of $c_{0}$ and $c_{1}$.

It is emphasized that, because of the above approximation, errors exist in the pre-yielding part in the force-velocity graph (when the velocity is small). However, higher accuracy can be achieved for larger damper force, which is more important for an inverse dynamics model.

\subsubsection{Piston Velocity Feedback (PVF) Algorithm}

If $F_{\text {Optimal }}(t)$ is realizable, that is it satisfies the passivity and limitation constraints described in 
Section 2.1, then the optimal input current $i(t)$ may be calculated as follows

$$
\begin{aligned}
& \text { As } \quad F_{\tau}(t)=\frac{c_{1}(t) \alpha(t) z_{u}}{c_{0}(t)+c_{1}(t)} \operatorname{sgn}[\dot{x}(t)] \\
& \text { and } \quad F_{\eta}(t)=\frac{c_{0}(t) c_{1}(t)}{c_{0}(t)+c_{1}(t)} \dot{x}(t) \approx \frac{c_{0}(t-\Delta t) c_{1}(t-\Delta t)}{c_{0}(t-\Delta t)+c_{1}(t-\Delta t)} \dot{x}(t) \text { denoted by } \tilde{F}_{\eta}(t)
\end{aligned}
$$

The input current is expected to vary continuously with time, and hence the above approximation only affects the accuracy of the viscous force coefficient (gradient of the post-yielding part of force-velocity graph). In fact, since the gradient would not vary very much in a short time interval as the current is continuously changing, the approximation of $F_{\eta}(t)$ by $\tilde{F}_{\eta}(t)$ is considered sufficiently accurate when $\Delta t \rightarrow 0$.

By using the above approximation, the optimal yield force can be calculated as

$$
F_{\tau}(t)=\left|F_{\text {Optimal }}(t)\right|-\left|\tilde{F}_{\eta}(t)\right|
$$

which is expected to be bounded by $F_{\tau}(\min )$ and $F_{\tau}(\max )$.

Due to the complexity of the function $F_{\tau}(t)$, large computational effort must be expended in order to obtain the optimal input current. Hence, another functional form of $F_{\tau}(t)$ has to be developed. As $F_{\tau}(t)$ is the force component that is mainly varied with the fluid yield stress, the same form of exponential function is proposed herein for $F_{\tau}(t)$ :

$$
F_{\tau}(t)=k_{4}-k_{5} e^{-k_{6} i(t)} \geq 0
$$

where $k_{4}, k_{5}$ and $k_{6}$ are constants. Similar to the case of modelling yield stress [refer Equation (15)], different configurations of MR dampers would result in different parameters $\left(k_{4}, k_{5}\right.$ and $\left.k_{6}\right)$ in Equation (24). The comparison between the proposed model and the experimental results for large-scale MR dampers [19] has been shown in Figures 2(c) and 2(d). The modelling accuracy is similar to the case of modelling yield stress, with higher accuracy for larger yield force. It is observed that the exponent is the same in modelling yield stress $\left(k_{3}\right)$ and yield force $\left(k_{6}\right)$, for the same damper, implying that the curvatures of the two relationships are the same. This finding can further verify the appropriateness of extending the 
proposed yield stress modelling of Equation (15) to yield force modelling of Equation (24).

Furthermore, the generic nature of the proposed exponential function has been further extended and reaffirmed by comparing with a small-scale MR damper recently proposed in Ref.[23] in 2005. The accuracy of the proposed model has been shown in Figure 2(e). Figures 2(a) - 2(e) can therefore ascertain the suitability and the generic nature of the proposed exponential functions [Equations (15) and (24)], as an alternative to model the MR fluid yield stress and the controllable yield force of MR damper. Hence, it can then be employed for the development of SID model for Bouc-Wen Hysteresis Model.

Substituting Equation (24) into Equation (23), the general SID model for obtaining the optimal input current $i(t)$ becomes

$$
i(t)=-\frac{1}{k_{6}} \ln \left[\frac{k_{4}-\left|F_{\text {Optimal }}(t)\right|+\left|\tilde{F}_{\eta}(t)\right|}{k_{5}}\right]
$$

\subsubsection{Damper Force Feedback (DFF) Algorithm}

In Equation (25), $\tilde{F}_{\eta}(t)$ is required for obtaining the optimal input current $i(t)$, and hence the piston velocity is required. As discussed above, an alternative procedure employing damper force feedback (DFF) would be more straightforward to implement.

Noting

$$
\left|\tilde{F}_{\eta}(t)\right|=\left|F_{\text {Actual }}(t)\right|-\left|F_{\tau}(t-\Delta t)\right|
$$

And substituting Equation (24) into Equation (26) and then into Equation (25), gives

$$
i(t)=-\frac{1}{k_{6}} \ln \left[\frac{\left|F_{\text {Actual }}(t)\right|-\left|F_{\text {Optimal }}(t)\right|}{k_{5}}+e^{-k_{6}(t(t-\Delta t)}\right]
$$

\section{Structure-damper-brace System Model}

For frame structures, one feasible way to implement MR dampers is to place them between the chevron brace and the floor diaphragm, as shown in Figure 3(a). Xu et al. [16] derived a mathematical model for the damper-chevron brace system, giving consideration to the stiffness of the chevron brace. In 
considering the damper and the chevron brace as a damper and spring connected in series [Figure 3(b)], the spring force in the brace is equal to the force on the piston of the damper, and hence

$$
F_{j}=C_{\eta_{j}} \cdot v_{0_{j}}+F_{\tau_{j}} \operatorname{sgn}\left(v_{0_{j}}\right)=K_{B_{j}}\left(x_{j}-x_{j-1}-d_{j}\right)
$$

where $x_{j}$ is the displacement of $j^{\text {th }}$ floor, $d_{j}$ is the piston displacement at $j^{\text {th }}$ floor and $K_{B j}$ is the horizontal stiffness of the chevron brace at $j^{\text {th }}$ floor.

The equations of motion for an $N$-degree-of-freedom frame structure with $m$ dampers subjected to ground acceleration $\ddot{x}_{g}$ are given by

$$
[M]\{\ddot{x}\}+[C]\{\dot{x}\}+\left([K]+[H]\left[K_{B}\right][H]^{T}\right)\{x\}-[H]\left[K_{B}\right]\{d\}=-[M]\{1\} \ddot{x}_{g}
$$

where $[M]$ is the structure's mass matrix, $[C]$ is its damping matrix, and $[K]$ is its stiffness matrix; $\left[K_{B}\right]$ is the $m \times m$ diagonal stiffness matrix for the chevron brace; $m$ is the number of storeys having MR dampers; $[H]$ is the $N \times m$ matrix converting the brace stiffness matrix into the global co-ordinate system; $\{x\},\{\dot{x}\}$, and $\{\ddot{x}\}$ are the $N \times 1$ displacement, velocity and acceleration vectors, respectively, of the structure; $\{d\}$ is the $m \times 1$ piston displacement vector of the MR dampers; and $\{1\}$ is an index vector with all its elements equal to 1 .

Equations (28) and (29) can be rewritten in the state-space form as

$$
\{\dot{z}\}=[A]\{z\}+[B]\{F\}+\{D\} \ddot{x}_{g}
$$

$$
\begin{array}{rlrl} 
& \{z\}=\left[\begin{array}{l}
\{x\} \\
\{\dot{x}\}
\end{array}\right] & {[A]=\left[\begin{array}{cc}
{[0]} & {[I]} \\
-[M]^{-1}[K] & -[M]^{-1}[C]
\end{array}\right]} \\
{[B]=\left[\begin{array}{c}
{[0]} \\
{[M]^{-1}[H]}
\end{array}\right]} & \{D\}=\left[\begin{array}{c}
\{0\} \\
-\{1\}
\end{array}\right]
\end{array}
$$

\section{LQR Optimal Force Control}

The LQR algorithm has been employed both for active control [13] and for semi-active control [24].

Using this algorithm, the optimal control force $\left\{F_{\text {Optimal }}\right\}$ for $\{F\}$ given in Equation (30) may be 
obtained by minimizing the following scalar performance index

$$
J=\int_{t_{0}}^{t_{f}}\left(\{z\}^{T}[Q]\{z\}+\{F\}^{T}[R]\{F\}\right) d t
$$

The time interval $\left[t_{0}, t_{f}\right]$ in the integral Equation (32) is defined to be longer than that of the external excitation. Also, $[Q]$ is a $2 N \times 2 N$ positive semi-definite matrices $([Q] \geq 0)$, and $[R]$ is an $m \times m$ positive definite matrix $([R]>0)$.

$[Q]$ and $[R]$ are weighting matrices and their values are selected depending on the relative importance given to the different terms in their contributions to the performance index $J$. Large values of $[Q]$ represent the desire of keeping the state vector close to the origin during the minimization interval $\left[t_{0}, t_{f}\right]$, whilst large values of $[R]$ imply a moderate level of control.

Solving the optimal control problem with $J$ defined by Equation (32) subjected to the constraint represented by Equation (30), results in a control force vector $\left\{F_{\text {Optimal }}\right\}$ regulated only by the state vector $z$, such that

$$
\left\{F_{\text {optimal }}\right\}=-[R]^{-1}[B]^{T}[P]\{z\}=[G]\{z\}
$$

where matrix $[G]$ represents the gain matrix; and matrix $[P]$ is the solution of the classical Riccati equation given by

$$
[P][A]+[A]^{T}[P]-[P][B][R]^{-1}[B]^{T}[P]+[Q]=0
$$

Upon substituting Equation (33) into Equation (30), the behaviour of the optimally controlled structure is described by

$$
\{\dot{z}\}=\left([A]+[B][G]\left\{\{z\}+\{D\} \ddot{x}_{g} ;\right.\right.
$$

It is evident from Equation (35) that the effect of closed-loop control becomes one of structural modifications, whereby the system matrix is changed from $[A]$ (open-loop system) to $[A]+[B][G]$ (closed-loop system). 


\section{Numerical Simulations}

In this section, the effectiveness of force tracking using SID model has been demonstrated through a series of numerical simulations, for both the Bingham plasticity model and the Bouc-Wen hysteresis model. A three-storey building model configured with a single large-scale MR damper, connected between the ground and the first floor, has been adopted. The large-scale 20-ton MR damper developed in Ref.[11] has been chosen, as they have provided all the essential details for simulation purpose. The building is subjected to the $1940 \mathrm{El}$ Centro and 1994 Northridge, California earthquake ground excitations, of which the frequency contents are different. The strong-motion duration of the two selected ground motions has been taken as 10 seconds [Figures 4(a) and 4(b)], which is sufficiently long for the desired purpose.

Three simulations have been carried out in order to show the robust performance to different shaking levels and frequency contents of ground motions. The first one is the $1940 \mathrm{El} \mathrm{Centro} \mathrm{earthquake} \mathrm{ground}$ excitation, without modification, with peak ground acceleration (PGA) of around $0.2 \mathrm{~g}$ [Figure 4(a)] Simulation 1; the second one is the 1994 Northridge earthquake ground excitation, with ground motion amplitude multiplied by four, in order to achieve a PGA of around $0.4 \mathrm{~g}$ [Figure 4(b)] - Simulation 2; and the third one is the $1940 \mathrm{El}$ Centro earthquake ground motion, with ground motion amplitude multiplied by three, in order to achieve a PGA of $0.6 \mathrm{~g}$ [not shown] - Simulation 3.

As the PVF and DFF algorithms for Bingham plasticity model are slightly different, the application of both algorithms would be demonstrated. However, the PVF and DFF algorithms for the Bouc-Wen hysteresis model are essentially identical, as no further modification has been made for DFF algorithm, hence only a single demonstration has been presented. On the other hand, as the performance of the two models is not expected to vary much with the frequency content and shaking level of the ground excitation, hence, only Simulation 1 would be performed for Bingham plasticity model, whilst all three simulations would be carried out for Bouc-Wen hysteresis model.

It is emphasised that the effectiveness of SID model should be demonstrated based on the force tracking accuracy, for which results have been shown for all simulations. However, for more information, the 
comparison of response reduction with other energy dissipation systems would also be demonstrated for one selected case - Simulation 1 for Bouc-Wen hysteresis model. The reason for not showing the comparison for all simulations is that this study is not intended to show the effectiveness of semi-active control using MR damper, over other energy dissipation systems.

The structural matrices are given as

$$
[M]=\left[\begin{array}{ccc}
50 & 0 & 0 \\
0 & 50 & 0 \\
0 & 0 & 50
\end{array}\right] \times 10^{3} \mathrm{~kg} \quad[K]=\left[\begin{array}{ccc}
40 & -20 & 0 \\
-20 & 40 & -20 \\
0 & -20 & 20
\end{array}\right] \times 10^{3} \frac{\mathrm{kN}}{\mathrm{m}} \quad \text { (36) and (37) }
$$

The structural damping ratio is assumed to be $1 \%$ of critical (lightly damped) and Rayleigh damping is assumed. The ratio of the chevron brace horizontal stiffness to the structure horizontal stiffness has been selected as three. The weighting matrix for structural response has been defined as

$$
[Q]=\left[\begin{array}{cccccc}
100 & 0 & 0 & 0 & 0 & 0 \\
0 & 10 & 0 & 0 & 0 & 0 \\
0 & 0 & 10 & 0 & 0 & 0 \\
0 & 0 & 0 & 10 & 0 & 0 \\
0 & 0 & 0 & 0 & 1 & 0 \\
0 & 0 & 0 & 0 & 0 & 1
\end{array}\right]
$$

As the parameters for the two types of damper models (described above) give different force-velocity relationships, individual parametric studies on the weighting coefficients $[R]$ have to be conducted, in order that large ranges of optimal yield stress/input current variation may be demonstrated. It is noted that, in practice, the weighting coefficient $[R]$ should be determined based on the local seismicity, hence, different $[R]$ is expected for different shaking levels. They are:

For the Bingham plasticity model:

$$
[R]=1 \times 10^{-11} \quad \text { for Simulation } 1
$$

For the Bouc-Wen hysteresis model

$$
[R]=3 \times 10^{-12} \quad \text { for Simulation } 1
$$




$$
\begin{array}{ll}
{[R]=4 \times 10^{-12}} & \text { for Simulation } 2 \\
{[R]=6 \times 10^{-12}} & \text { for Simulation } 3
\end{array}
$$

The integration time step has been set as $0.002 \mathrm{~s}$, which is sufficiently small to minimize the integration error, while the sampling time step has been set as $0.02 \mathrm{~s}$.

\subsection{Bingham Plasticity Model}

A numerical simulation employing the Bingham plasticity model has been demonstrated using the model parameters provided in Yang et al. [11]. A summary of the model parameters has been given in Table I.

\subsubsection{PVF Algorithm}

Figure 5(a) confirms that very good tracking of the optimal force with minimal discrepancy can be expected when the optimal control force obtained is smaller than the off-state force, that is when $\left|F_{\text {Optimal }}(t)\right|<\left|F_{\text {min. }}(t)\right|$. The MR fluid yield stress variation and the force tracking error have been shown in Figures 5(b) and 5(c), respectively. It is expected that the tracking error is large only when the yield stress is low, and hence higher accuracy can be obtained for larger damper force, for which high accuracy is more important.

Furthermore, another way to investigate the effectiveness of force tracking when employing the proposed SID model is to compare the peak response reduction between active and semi-active control using MR damper, as given in Table II. As the active control forces are exactly the optimal control forces that the MR damper is intended to produce, the close values of the response reduction between the two cases indicate very good force tracking when employing the SID model.

On the other hand, the displacement and acceleration time histories of uncontrolled and semi-actively controlled cases for the first and third floors have been shown in Figures 6 and 7, respectively. 


\subsubsection{DFF Algorithm}

Similar to the previous section, Figure 8(a) shows that the force tracking employing the DFF algorithm is also very good. The force tracking error is shown in Figure 8(b), with somewhat larger error in comparison with the PVF algorithm. It is noted that the variation of MR fluid yield stress is very similar to that using PVF algorithm, so, such figure has not been shown for this case. Moreover, the effectiveness of response (displacement, velocity and acceleration) reductions using the DFF algorithm is also very similar to those using the PVF algorithm.

\subsection{Bouc-Wen Hysteresis Model}

For the large-scale 20-ton MR damper developed in Ref.[11], the functional dependence of the parameters $\alpha, c_{0}$ and $c_{1}$ on the input current has been assumed to have the form of a third-order polynomial. The equations for $\alpha, c_{0}$ and $c_{1}$ are as follows

$$
\begin{aligned}
& \alpha(i)=16566 i^{3}-87071 i^{2}+168326 i+15114 \\
& c_{0}(i)=437097 i^{3}-1545407 i^{2}+1641376 i+457741 \\
& c_{1}(i)=-9363108 i^{3}+5334183 i^{2}+48788640 i-2791630
\end{aligned}
$$

and the remaining parameters have been given in Table III. It is noted that the form of these three equations is only the assumption made in Ref.[11], for capturing the properties of the MR fluid used in their study, whilst different assumptions can be made, such as in Ref.[23]. Hence, this would not restrict the application of the SID model developed in this study.

The relationship between the viscous force coefficient and the input current has been shown in Figure 9 . It is observed that the viscous force coefficient varies smoothly with the input current; especially when the input current is greater than 0.5 A. Hence, the simplification made in Equation (22) is considered to be sufficiently accurate, as the input current is expected to vary continuously with time.

It is noted that there is an obvious decrease of the viscous force coefficient with the increase of input current for small input current ( $<0.1 \mathrm{~A})$. By investigating Equation (22), the viscous force coefficient is a 
function of $c_{0}$ and $c_{1}$ [Equations (40b) and (40c)], which were determined individually by optimal identification by Yang et al. [11]. The negative values of the coefficient $c_{1}$ computed for input current smaller than 0.057 A would account for the decrease of the viscous force coefficient for small input current.

Regarding the relationship between the yield force and the input current, the proposed exponential function has been obtained for this large-scale MR damper, wherein $k_{4}$ and $k_{5}$ have both been chosen as $1.5 \times 10^{5}$, and $k_{6}$ as 1.5 , giving

$$
F_{\tau}(t)=1.5 \times 10^{5}\left[1-e^{-1.5 i(t)}\right]
$$

It is seen in Figure 10 that the proposed exponential function [Equation (41)] can fit very well with the actual function $F_{\tau}(t)$ [Equation (21)], whilst higher accuracy within the region of larger yield force is imposed. The latter feature is especially important for an inverse dynamics model. It is noted that, for better fitting, the optimal input current has been set to zero when the calculated value is less than $0.1 \mathrm{~A}$.

By Equation (25) and Equation (27), the SID model becomes

$$
\begin{gathered}
i(t)=-\frac{2}{3} \ln \left[1-\frac{\left|F_{\text {Optimal }}(t)\right|-\left|\tilde{F}_{\eta}(t)\right|}{1.5 \times 10^{5}}\right] \\
\text { or } \quad i(t)=-\frac{2}{3} \ln \left[\frac{\left|F_{\text {Actual }}(t)\right|-\left|F_{\text {Optimal }}(t)\right|}{1.5 \times 10^{5}}+e^{-1.5 i(t-\Delta t)}\right]
\end{gathered}
$$

The PVF [Equations (25) and (42)] and DFF [Equations (27) and (43)] algorithms for the Bouc-Wen hysteresis model are essentially identical, as no further modification has been made for DFF algorithm, hence only a single demonstration has been presented for each of the three simulations.

Simulation 1 is the 1940 El Centro earthquake ground excitation, without modification, with PGA of around $0.2 \mathrm{~g}$. Figure 11(a) shows good tracking of the optimal control force. A discrepancy, similar to the Bingham model, can be expected when the optimal control force is smaller than the off-state force. The input current variation and the force tracking error have further been shown in Figures 11(b) and 11(c), respectively. It is expected that the tracking error is larger when the input current is zero, and hence a 
higher degree of accuracy can be obtained for larger damper force.

On the other hand, the comparison of peak response reduction between active and semi-active control using MR damper has been presented in Table IV. The close values of the peak response reduction between the two cases indicate very good force tracking when employing the proposed SID model.

Further comparison of response reduction with other energy dissipation systems has been done here. The first one is a control system with an actuator providing a constant force of $70 \mathrm{kN}$, which is determined based on the time-average optimal force calculated for the active and semi-active control systems [refers the optimal force time history as shown in Figure 11(a)]. The second one is a passive control system with a linear viscous damper, connected between the ground and the first floor, designed to give a damping ratio of about $20 \%$ of critical. The displacement and acceleration time histories, together with the uncontrolled and semi-actively controlled cases for the first and third floors have been presented in Figures 12 and 13, respectively. The peak response reduction ratio of the two additional energy dissipation systems has been presented in Table V.

Simulation 2 is the 1994 Northridge earthquake ground excitation, with ground motion amplitude multiplied by four, so as to achieve a PGA of around $0.4 \mathrm{~g}$. Figure 14(a) shows excellent force tracking, whilst input current variation and force tracking error have also been shown in Figures 14(b) and 14(c), respectively. Finally, Simulation 3 is the 1940 El Centro earthquake ground motion, with ground motion amplitude multiplied by three, in order to achieve a PGA of 0.6 g. Figures 15(a) - 15(c) show, respectively, the force tracking, input current variation and force tracking error. The peak response reduction ratio of the two simulations has been presented in Table VI.

The results presented above have shown that the proposed SID model is a simple, yet powerful, tool to emulate the optimal control force. The generic nature of SID model has been verified by its applications to different earthquake scenario of different frequency contents, and also to a wide range of ground shaking intensity, with PGA from 0.2 to $0.6 \mathrm{~g}$. The effectiveness of response reduction using MR fluid damper with SID model has been shown to be almost identical to the case of active control, which is undoubtedly much better than other passive dissipation system or an actuator producing a constant 
control force.

\section{Conclusions}

In this study, simplified inverse dynamics (SID) models for MR fluid dampers have been developed with respect to both the Bingham plasticity model and the Bouc-Wen hysteresis model, based mainly on time-continuity properties. SID models are employed to obtain the optimal input current for the MR fluid damper, in order to emulate the optimal force. For the Bingham plasticity model, the proposed SID model is primarily used to calculate the optimal fluid yield stress. Together with the proposed exponential relationship between the MR fluid yield stress and the input current, the desirable control forces obtained from any optimal control algorithms can be realised. Regarding the Bouc-Wen hysteresis model, the optimal input current could be obtained using the proposed SID model, with the proposed exponential function for the controllable yield force of the MR damper. The generic nature of the two proposed exponential functions have been explicitly demonstrated.

For each model, the piston velocity feedback (PVF) algorithm and damper force feedback (DFF) algorithm have been formulated. The effectiveness of force tracking using SID model has been evaluated through a series of numerical simulations. A multi-storey frame structure with MR damper-brace systems, using a large-scale 20-ton MR damper, has been adopted. Numerical results show that the MR damper can produce forces very close to the optimal control force and the response reduction is very close to the case of fully active control. It has been shown that the proposed SID model is a simple, yet powerful, tool to emulate the optimal control force, yet consuming little computational effort. The generic nature of SID model has been verified by its applications to different frequency contents, and also to a wide range of ground shaking intensity. The effectiveness of response reduction using MR fluid damper with SID model has been shown to be almost identical to the case of active control.

As mentioned in the introductory section, MR fluids can reversibly change from free flowing, linear viscous liquids to semi-solids having a controllable yield strength, when exposed to a magnetic field. Hence, a time delay should be expected between the instant that a decision is made to develop a certain 
current computed by SID model, to developing the current, and finally to developing the desired damping force. To improve the response time, Ref.[19] has proposed a back-driven current approach, and experimentally shown to be effective. The back-driven current strategy is activated when the desired force is not dissipative and the error between the measured and desired forces is large. This technique can forcibly reduce the magnetic field by applying a negative current, and hence, the damper response can be improved significantly. It has been shown that the use of the back-driven current approach requires less than $0.1 \mathrm{sec}$ to command the damper force from $158.5 \mathrm{kN}$ to the off-state force of $7.85 \mathrm{kN}$, whilst a full second is required if no back-driven current is applied. Further details can be obtained in Ref.[19].

\section{Acknowledgements}

The work described in this paper has been fully supported by the URC (University Research Committee) of The University of Hong Kong through Seed Funding for Basic Research (2002-2003).

\section{References}

[1] Hrovat D, Barak P, Rabins M. Semi-active versus passive or active tuned mass dampers for structural control. Journal of Engineering Mechanics ASCE 1983; 109(3):691-705.

[2] Symans MD, Constantinou MC. Semi-active control systems for seismic protection of structures: a state-of-the-art review. Engineering Structures 1999; 21:469-487.

[3] Gavin GP, Hanson RD, Filisko FE. Electrorheological dampers. Part I: analysis and design. Journal of Applied Mechanics ASME 1996; 63(9):669-675.

[4] Gavin GP, Hanson RD, Filisko FE. Electrorheological dampers. Part II: testing and modelling. Journal of Applied Mechanics ASME 1996; 63(9):676-682.

[5] Dyke SJ, Spencer BF Jr, Sain MK, Carlson JD. Seismic response reduction using magnetorheological dampers. Proceedings of the IFAC World Congress, San Francisco, CA, June 30-July 5, 1996.

[6] Dyke SJ, Spencer BF Jr, Sain MK, Carlson JD. An experimental study of MR dampers for seismic protection. Smart Materials \& Structures 1998; 7(5):693-703.

[7] Jung, HJ, Spencer BF Jr, Ni, YQ, Lee IW. State-of-the-art of semiactive control systems using MR fluid dampers in civil engineering applications. Structural Engineering and Mechanics 2004; 17(3-4):493-526.

[8] Kurata N, Kobori T, Takahashi M, Niwa N. Actual seismic response controlled building with semi-active damper system. Earthquake Engineering and Structural Dynamics 1999; 28:1427-1448. 
[9] Yang JN, Wu JC, Li Z. Control of seismic excited buildings using active variable stiffness systems. Engineering Structures 1996; 18(8):589-596.

[10] Spencer BF Jr, Yang G, Carlson JD, Sain MK. 'Smart' dampers for seismic protection of structures: a full-scale study. Proc. of the $2^{\text {nd }}$ World Conference on Structural Control, Vol.1, Kyoto, Japan, 1998: 417-426.

[11] Yang G, Spencer BF Jr, Carlson JD, Sain MK. Large-scale MR fluid dampers: modeling and dynamic performance considerations. Engineering Structures 2002; 24:309-323.

[12] Chen ZQ, Wang XY, Ko JM, Ni YQ, Spencer BF, Yang G, Hu JH. MR damping system for mitigating wind-rain induced vibration on Dongting Lake cable-stayed bridge. Wind and Structures 2004; 7(5):293-304.

[13] Soong TT. Active Structural Control: Theory and Practice. Wiley: New York, U.S.A., 1990.

[14] Jansen LM, Dyke SJ. Semi-active control strategies for MR dampers: A comparative study. Journal of Engineering Mechanics ASCE 2000; 126(8):795-803.

[15] Chang CC, Zhou L. Neural network emulation of inverse dynamics for a magnetorheological damper. Journal of Structural Engineering ASCE 2002; 128(2):231-239.

[16] Xu YL, Qu WL, Ko JM. Seismic response control of frame structures using magnetorheological/electrorheological dampers. Earthquake Engineering and Structural Dynamics 2000; 29:557-575.

[17] Phillips RW. Engineering applications of fluids with a variable yield stress. Ph.D. dissertation, University of California, Berkeley, CA., 1969.

[18] Ni YQ, Chen Y, Ko JM, Cao DQ. Neuro-control of cable vibration using semi-active magnetorheological dampers. Engineering Structures 2002; 24:295-307.

[19] Yang G. Large-Scale Magnetorheological Fluid Damper for Vibration Mitigation: Modeling, Testing and Control. Ph.D. dissertation, University of Notre Dame, 2001.

[20] Spencer BF Jr, Dyke SJ, Sain MK, Carlson JD. Phenomenological model for magnetorheological dampers. Journal of Engineering Mechanics ASCE 1997, 123(3):230-238.

[21] Wen YK. Method for random vibration of hysteretic systems. Journal of the Engineering Mechanics Division ASCE 1976, 102, EM2, 249-263.

[22] Spencer BF Jr. Reliability of randomly excited hysteretic structures. Lecture Notes in Engineering, 21, CA Brebbia, SA Orzag, Eds. Springer Verlag, Berlin, 1986.

[23] Shen Y, Golnaraghi MF, Heppler GR. Analytical and experimental study of the response of a suspension system with a magnetorheological damper. Journal of Intelligent Material Systems and Structures 2005; 16(2):135-147.

[24] Sadek F, Mohraz B. Semiactive control algorithms for structures with variable dampers. Journal of Engineering Mechanics ASCE 1998; 124(9):981-990. 


\section{Figure Captions}

Figure 1(a).Semi-active MR damper dissipative criteria.

Figure 1(b).Semi-active MR damper realizable force limits.

Figure 2. Comparison between the proposed exponential functions [Equations (15) and (24)] and the experimental results: (a, b) MR fluid yield stress of the four different configurations of large-scale MR dampers [19]; (c, d) Controllable yield force of the four different configurations of large-scale MR dampers [19]; (e) Controllable yield force of small-scale MR damper [23].

Figure 3(a). Schematic diagram of a three-storey building model with damper-brace system [16].

Figure 3(b).Mechanical model of damper-brace system [16].

Figure 4. (a) Simulation 1 - 1940 El Centro; (b) Simulation 2 - 1994 Northridge (amplitude multiplied by 4), California earthquake ground excitations.

Figure 5. Bingham model - Simulation 1 - Piston Velocity Feedback (PVF) Algorithm: (a) Force tracking; (b) MR fluid yield stress variation; (c) Tracking error.

Figure 6. Bingham model - Simulation 1 - Uncontrolled and semi-actively controlled displacement time histories: (a) First floor; (b) Third floor.

Figure 7. Bingham model - Simulation 1 - Uncontrolled and semi-actively controlled acceleration time histories: (a) First floor; (b) Third floor.

Figure 8. Bingham model - Simulation 1 - Damper Force Feedback (DFF) Algorithm: (a) Force Tracking; (b) Tracking error.

Figure 9. Bouc-Wen hysteresis model - Viscous Force Coefficient $C \eta$ versus Current $i$ (Large-scale MR damper) [11].

Figure 10. Bouc-Wen hysteresis model - Yield Force $F \tau$ versus Current $i$ (Large-scale MR damper) [11].

Figure 11. Bouc-Wen hysteresis model - Simulation 1: (a) Force tracking; (b) Input current variation; (c) Tracking error.

Figure 12. Bouc-Wen hysteresis model - Simuation 1 - Uncontrolled and semi-actively controlled displacement time histories: (a) First floor; (b) Third floor.

Figure 13. Bouc-Wen hysteresis model - Simulation 1 - Uncontrolled and semi-actively controlled acceleration time histories: (a) First floor; (b) Third floor.

Figure 14. Bouc-Wen hysteresis model - Simulation 2: (a) Force tracking; (b) Input current variation; (c) Tracking error.

Figure 15. Bouc-Wen hysteresis model - Simulation 3: (a) Force tracking; (b) Input current variation; (c) Tracking error. 
Table I. Model parameters of the large-scale 20-ton MR damper (Bingham model) [11].

\begin{tabular}{cccccccc}
\hline$L$ & $h$ & $w$ & $A_{p}$ & $\eta$ & $F_{f}$ & $\tau_{\max }$ & $\tau_{\min }$ \\
\hline $8.4 \mathrm{~cm}$ & $2 \mathrm{~mm}$ & $0.632 \mathrm{~m}$ & $271 \mathrm{~cm}^{2}$ & $1.3 \mathrm{~Pa}-\mathrm{s}$ & $6.34 \mathrm{kN}$ & $62 \mathrm{kPa}$ & $0.05 \mathrm{kPa}$ \\
\hline
\end{tabular}

Table II. Comparison of the reduction of peak responses of Simulation 1 between active and semi-active control using MR damper (Bingham model).

\begin{tabular}{lcccc}
\hline & Floor & Active $(\%) *$ & Semi-active $(\%) *$ & Difference $(\%) \#$ \\
\hline Displacement & $1^{\text {st }}$ & 44.5 & 45.3 & 0.8 \\
& $2^{\text {nd }}$ & 48.4 & 49.4 & 1.0 \\
& $3^{\text {rd }}$ & 49.8 & 51.3 & 1.5 \\
\hline Acceleration & $1^{\text {st }}$ & 48.1 & 43.7 & -4.4 \\
& $2^{\text {nd }}$ & 49.3 & 49.2 & -0.1 \\
& $3^{\text {rd }}$ & 48.1 & 51.4 & 3.3 \\
\hline
\end{tabular}

* Values are the peak responses of the controlled case compared with the uncontrolled case.

\# Positive values indicate better performance under active control than by semi-active control. 
Table III. Model parameters of the large-scale 20-ton MR damper (Bouc-Wen model) [11].

\begin{tabular}{cccc}
\hline$A$ & $\beta$ & $\gamma$ & $n$ \\
\hline $2679.0 \mathrm{~m}^{-1}$ & $647.46 \mathrm{~m}^{-1}$ & $647.46 \mathrm{~m}^{-1}$ & 10 \\
\hline
\end{tabular}

Table IV. Comparison of the reduction of peak responses of Simulation 1 between active and semi-active control using MR damper (Bouc-Wen model).

\begin{tabular}{lcccc}
\hline & Floor & Active $(\%) *$ & Semi-active $(\%)$ & Difference $(\%) \#$ \\
\hline Displacement & $1^{\text {st }}$ & 26.6 & 28.2 & 1.6 \\
& $2^{\text {nd }}$ & 33.1 & 35.0 & 1.9 \\
& $3^{\text {rd }}$ & 35.5 & 37.3 & 1.8 \\
\hline Acceleration & $1^{\text {st }}$ & 34.6 & 32.4 & -2.2 \\
& $2^{\text {nd }}$ & 34.1 & 40.5 & 6.4 \\
& $3^{\text {rd }}$ & 38.5 & 40.2 & 1.7 \\
\hline
\end{tabular}

* Values are the peak responses of the controlled case compared with the uncontrolled case. \# Positive values indicate better performance under active control than by semi-active control. 
Table V. Reduction of peak responses of Simulation 1 of the two energy dissipation systems.

\begin{tabular}{lccc}
\hline & Floor & Constant force $70 \mathrm{kN}(\%) *$ & Passive $20 \%$ Critical $(\%) *$ \\
\hline Displacement & $1^{\text {st }}$ & 43.7 & 73.1 \\
& $2^{\text {nd }}$ & 43.8 & 73.8 \\
& $3^{\text {rd }}$ & 44.2 & 74.3 \\
\hline Acceleration & $1^{\text {st }}$ & 64.8 & 69.3 \\
& $2^{\text {nd }}$ & 60.6 & 73.7 \\
& $3^{\text {rd }}$ & 51.8 & 69.8 \\
\hline
\end{tabular}

* Values are the peak responses of the controlled case compared with the uncontrolled case.

Table VI. Reduction of peak responses of Simulations 2 and 3 using MR damper (Bouc-Wen model).

\begin{tabular}{lccc}
\hline & Floor & Simulation 2 $(\%) *$ & Simulation 3 $(\%) *$ \\
\hline Displacement & $1^{\text {st }}$ & 27.9 & 36.1 \\
& $2^{\text {nd }}$ & 33.1 & 40.2 \\
& $3^{\text {rd }}$ & 34.4 & 42.0 \\
\hline Acceleration & $1^{\text {st }}$ & 39.9 & 34.1 \\
& $2^{\text {nd }}$ & 48.1 & 39.9 \\
& $3^{\text {rd }}$ & 40.6 & 42.0 \\
\hline
\end{tabular}

* Values are the peak responses of the controlled case compared with the uncontrolled case. 


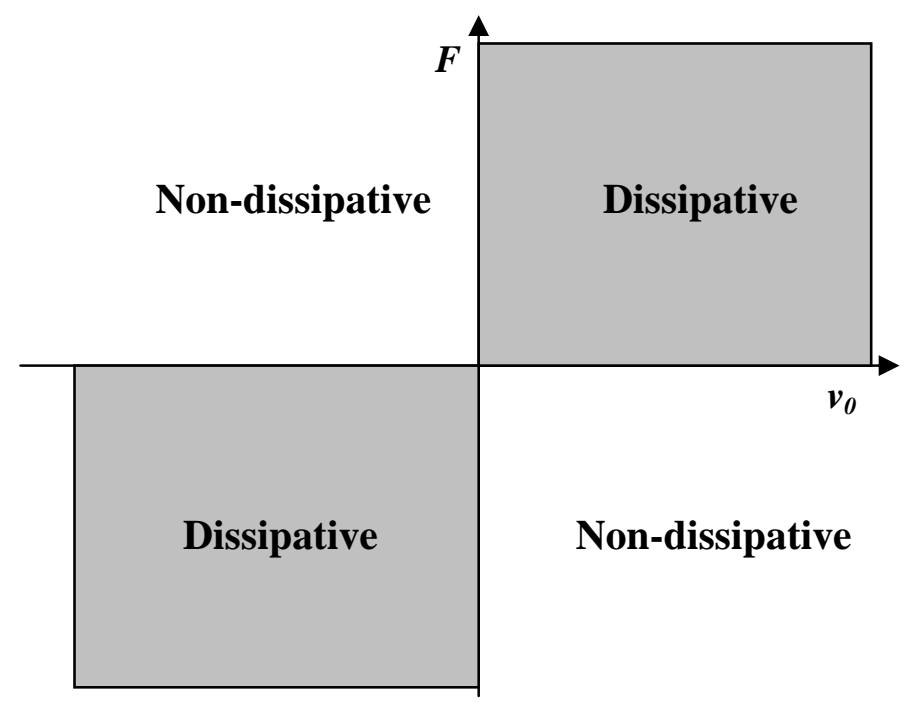

Figure 1(a). Semi-active MR damper dissipative criteria.

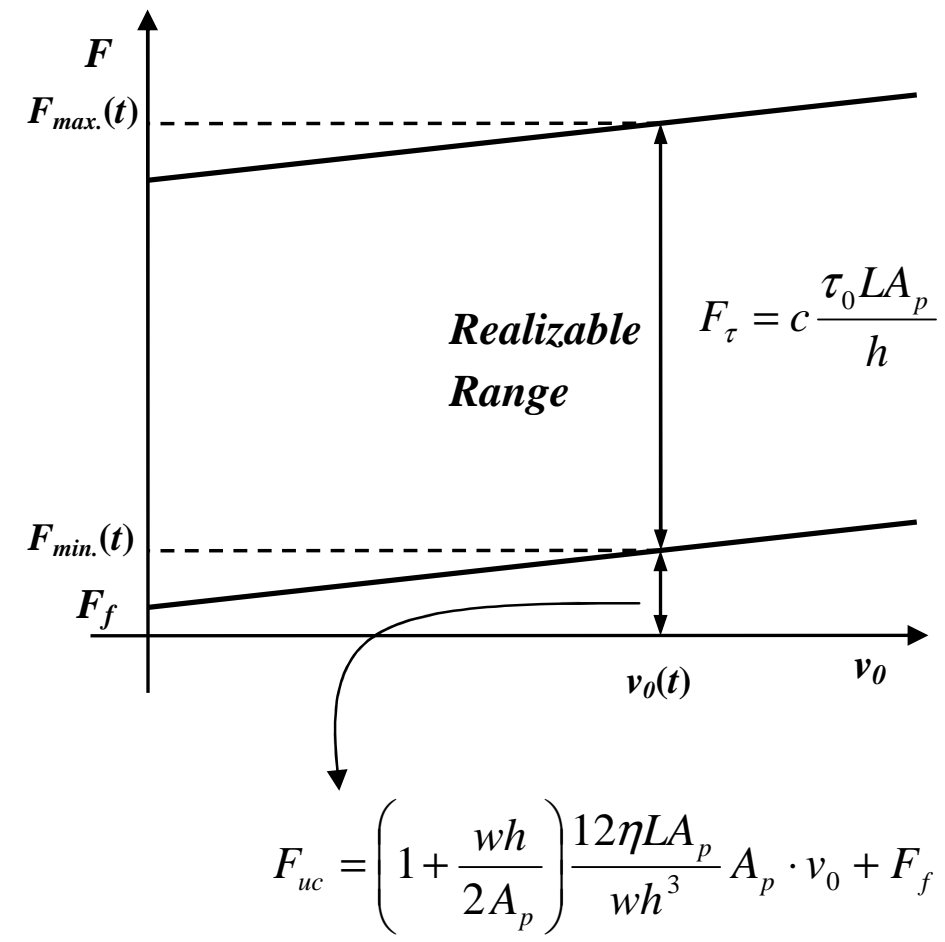

Figure 1(b). Semi-active MR damper realizable force limits. 

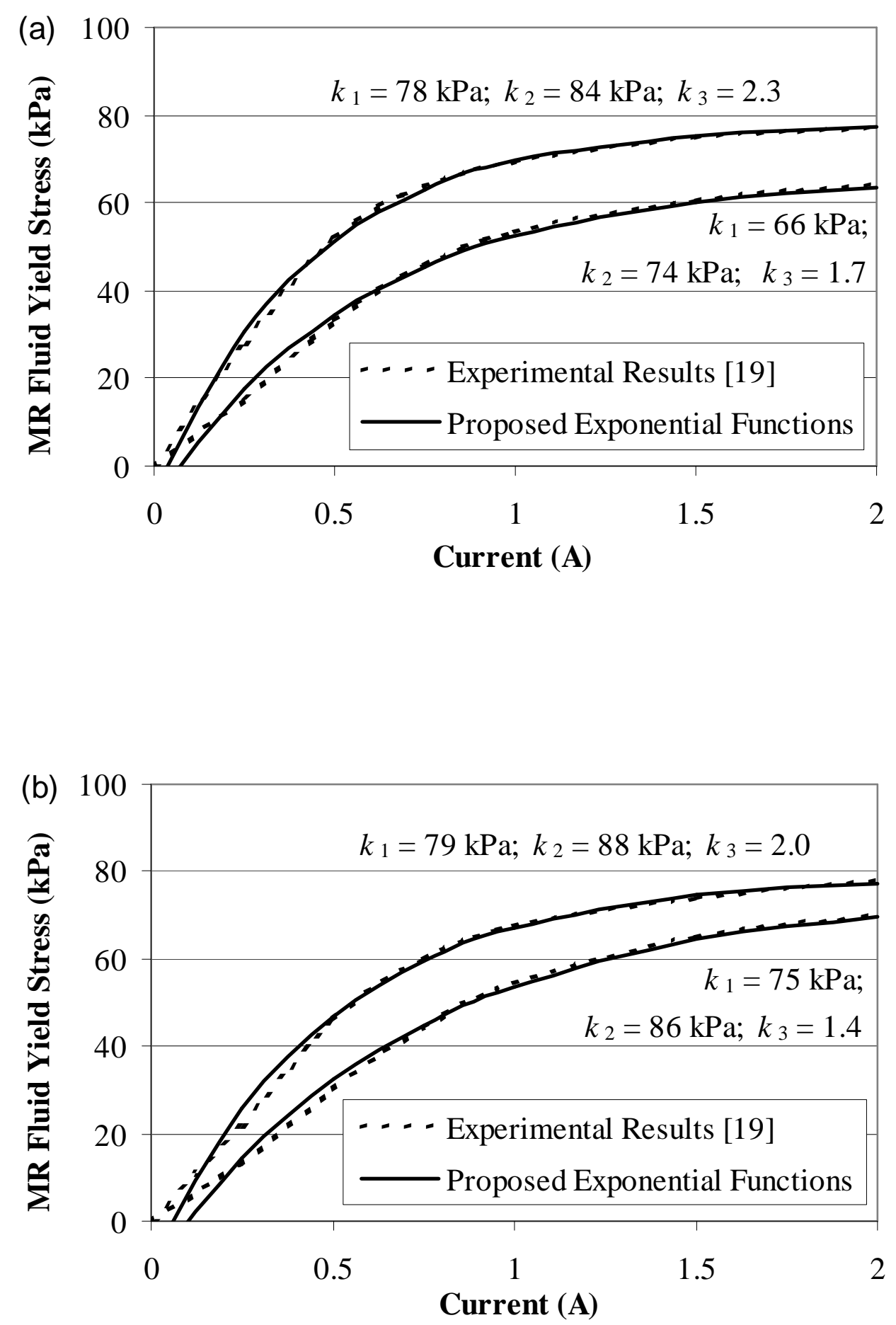

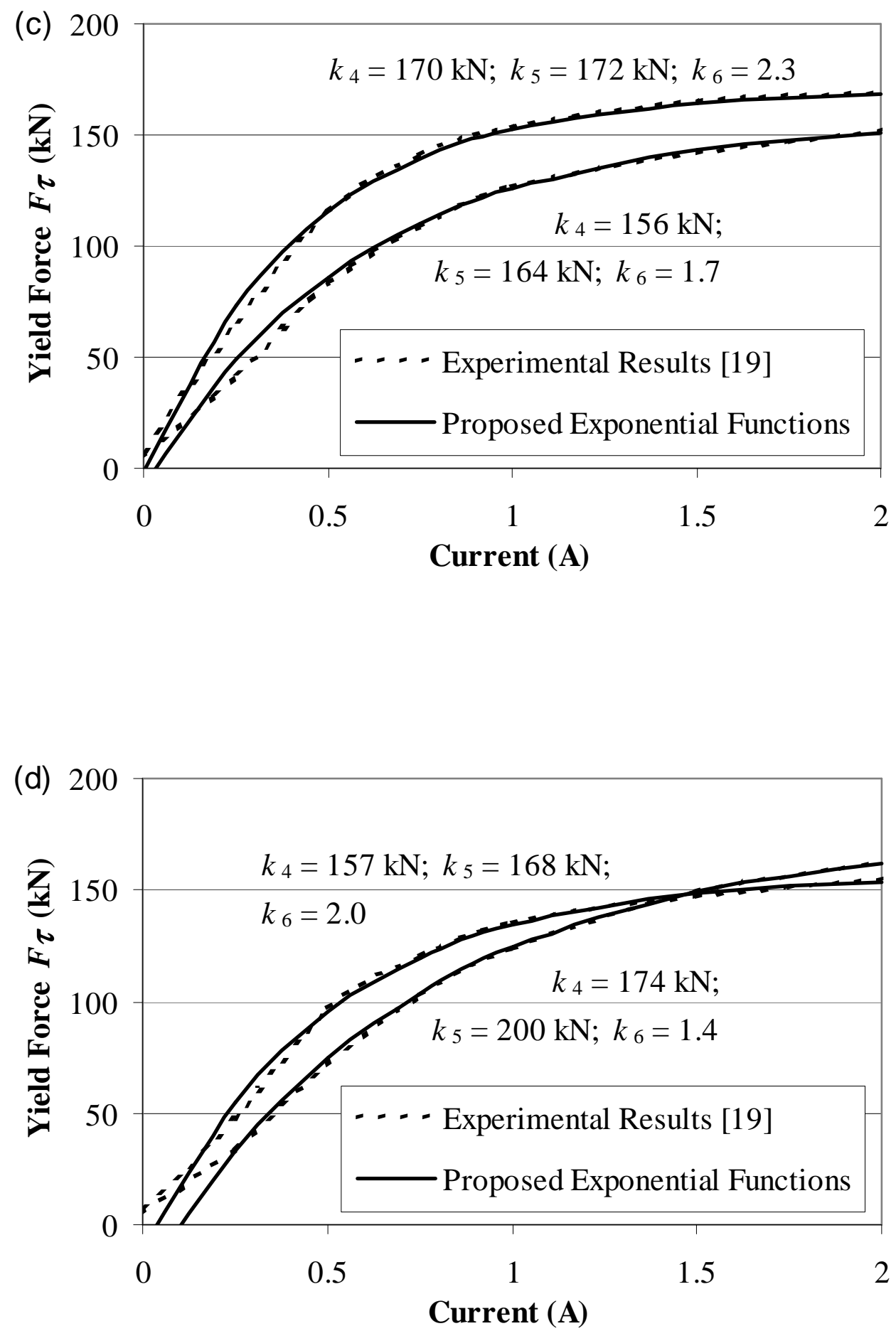


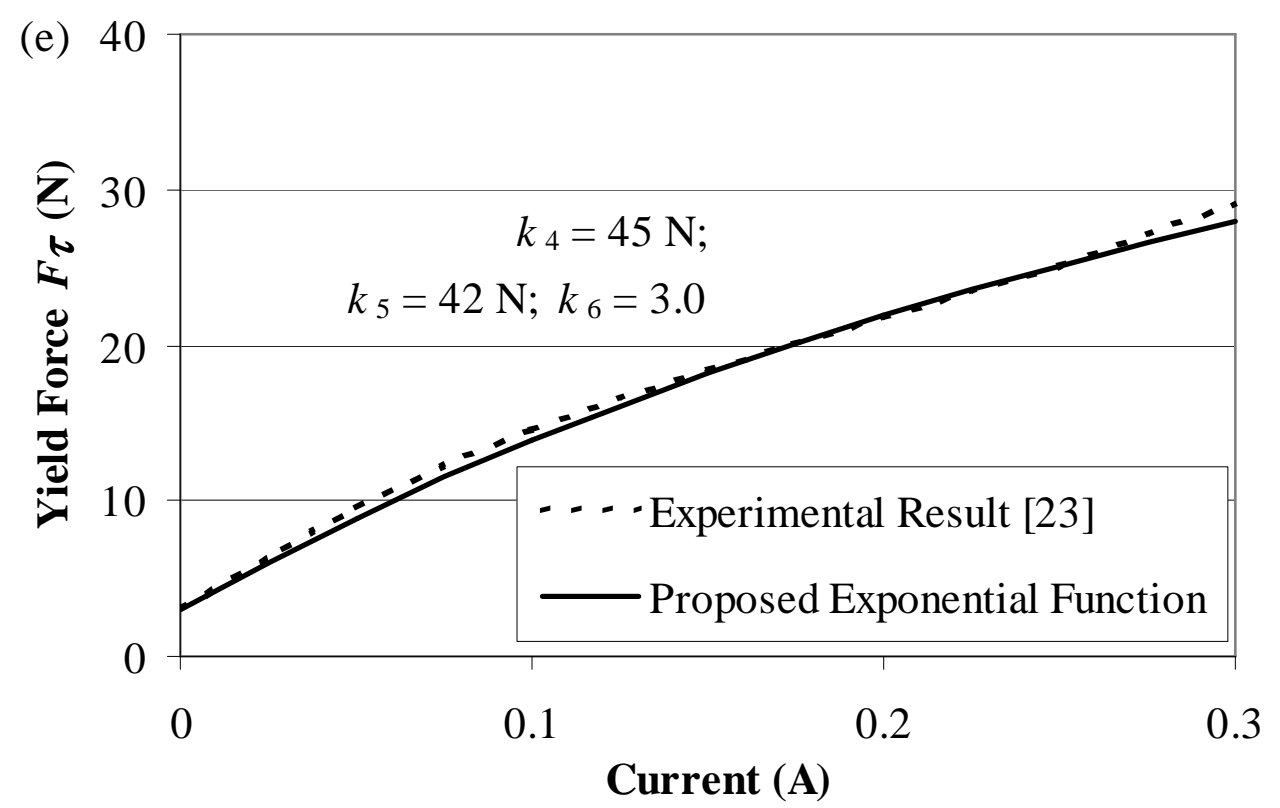

Figure 2. Comparison between the proposed exponential functions [Equations (15) and (24)] and the experimental results: (a, b) MR fluid yield stress of the four different configurations of large-scale MR dampers [19]; (c, d) Controllable yield force of the four different configurations of large-scale MR dampers [19]; (e) Controllable yield force of small-scale MR damper [23]. 


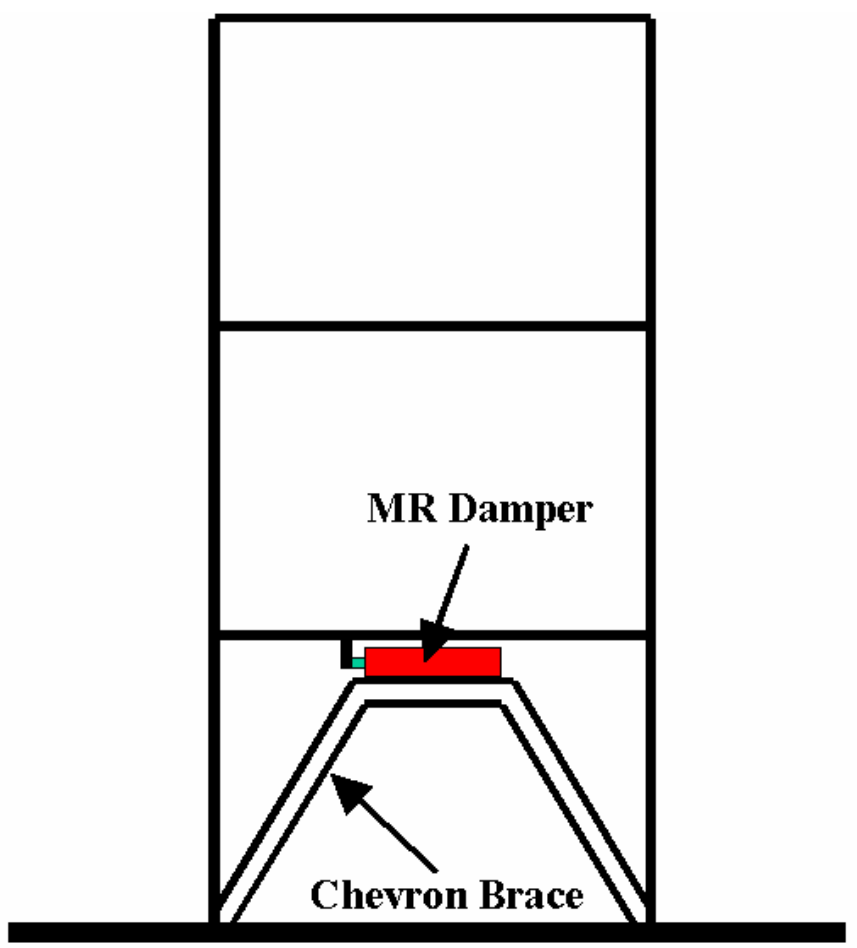

Figure 3(a). Schematic diagram of a three-storey building model with damper-brace system [16].

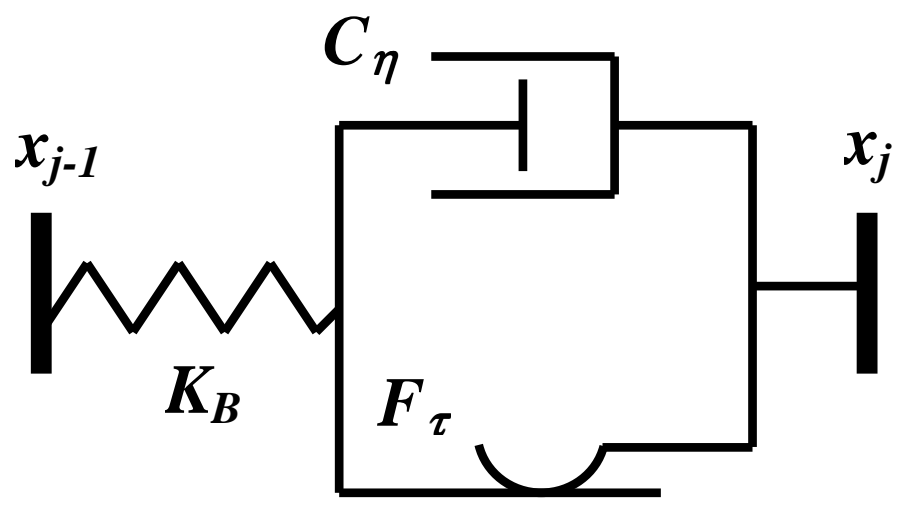

Figure 3(b). Mechanical model of damper-brace system [16]. 

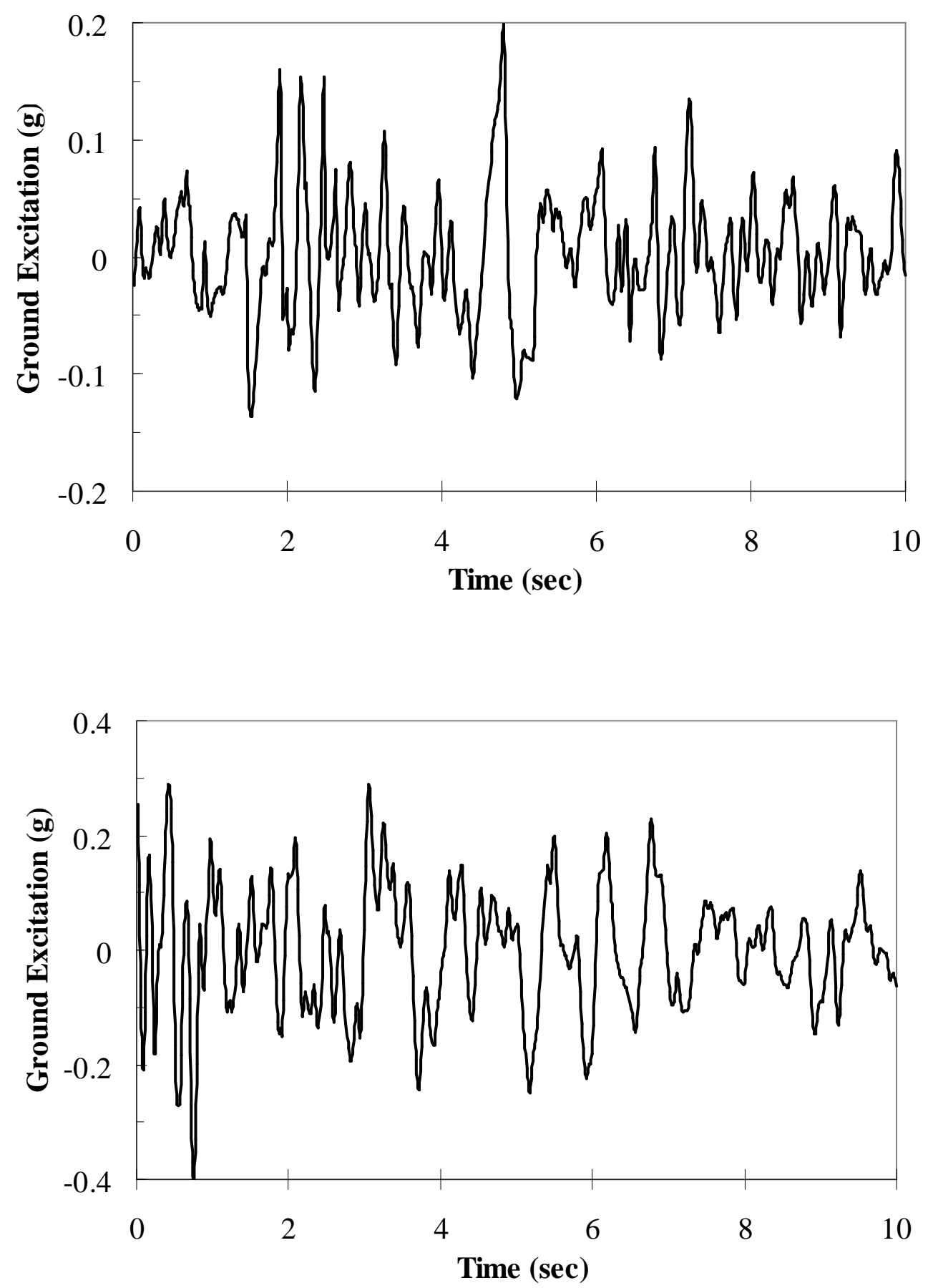

Figure 4. (a) Simulation 1 - 1940 El Centro; (b) Simulation 2 - 1994 Northridge (amplitude multiplied by 4), California earthquake ground excitations. 

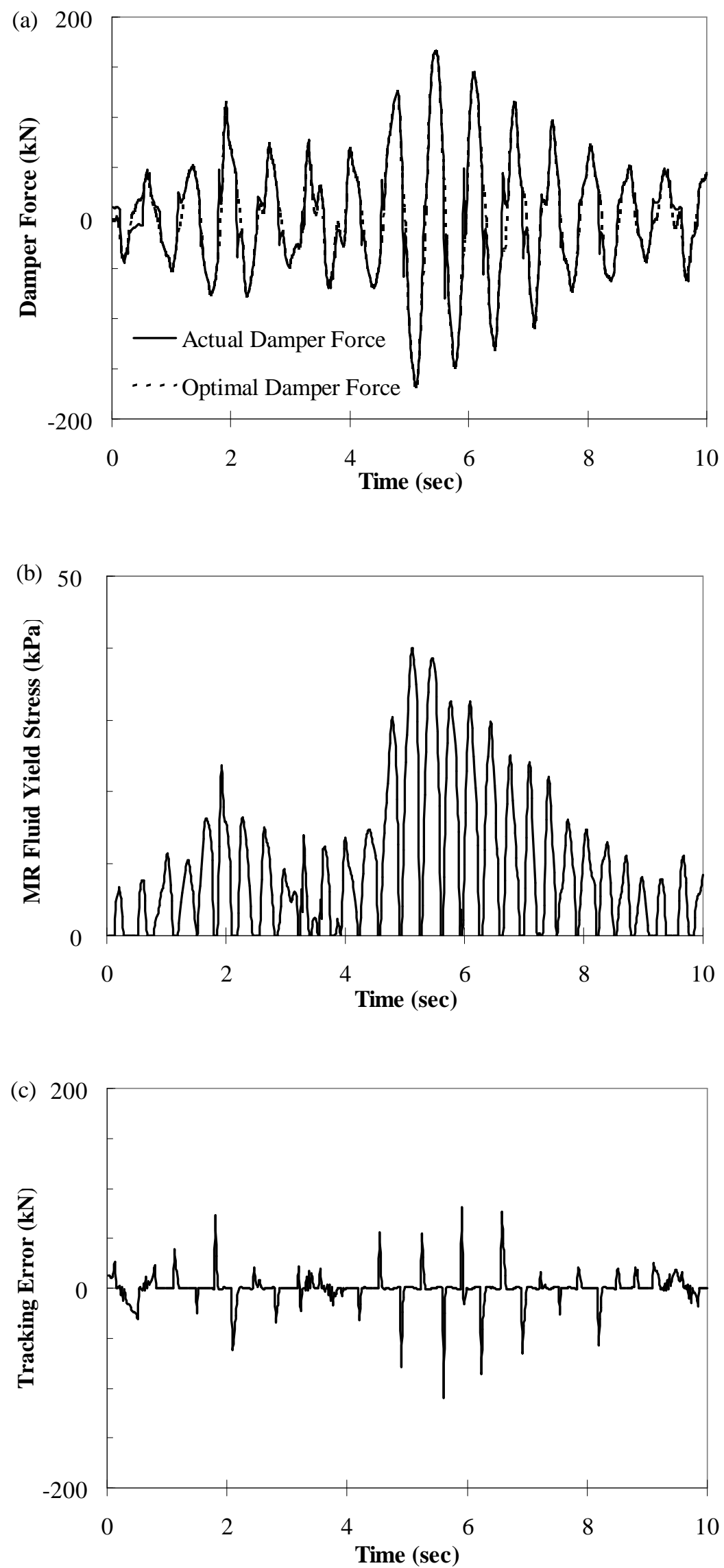

Figure 5. Bingham model - Simulation 1 - Piston Velocity Feedback (PVF) Algorithm:

(a) Force tracking; (b) MR fluid yield stress variation; (c) Tracking error. 

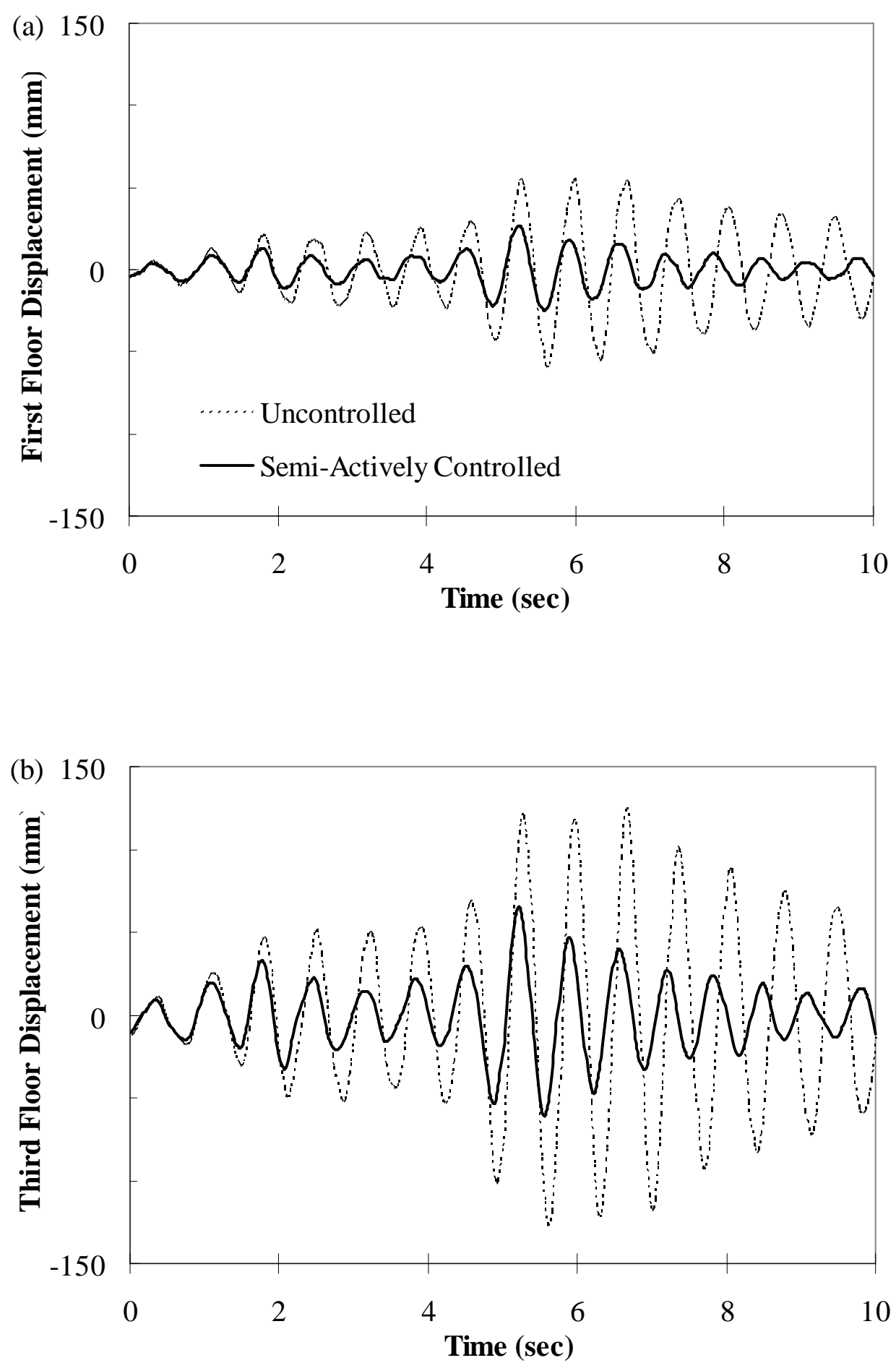

Figure 6. Bingham model - Simulation 1 - Uncontrolled and semi-actively controlled displacement time histories: (a) First floor; (b) Third floor. 

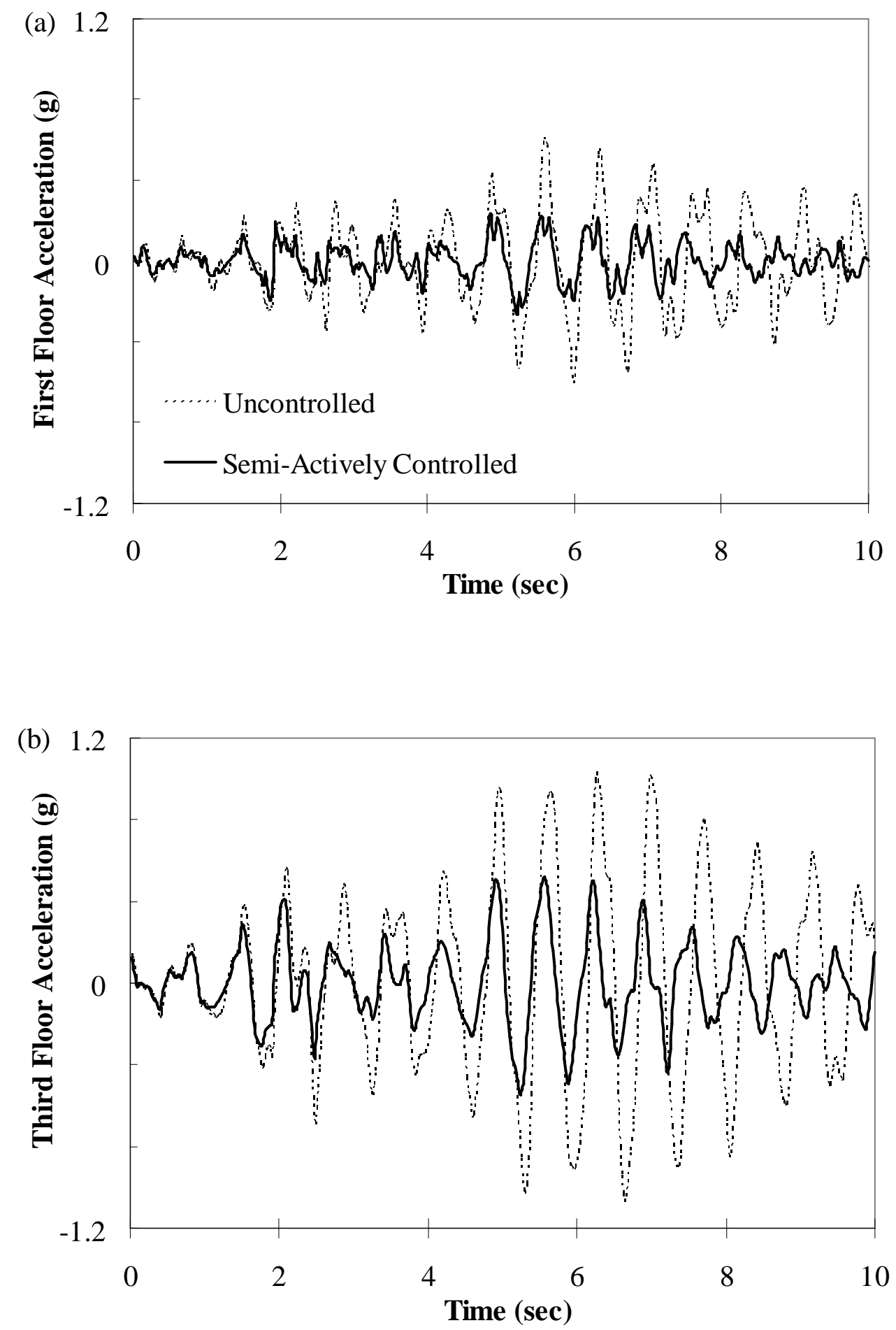

Figure 7. Bingham model - Simulation 1 - Uncontrolled and semi-actively controlled acceleration time histories: (a) First floor; (b) Third floor. 

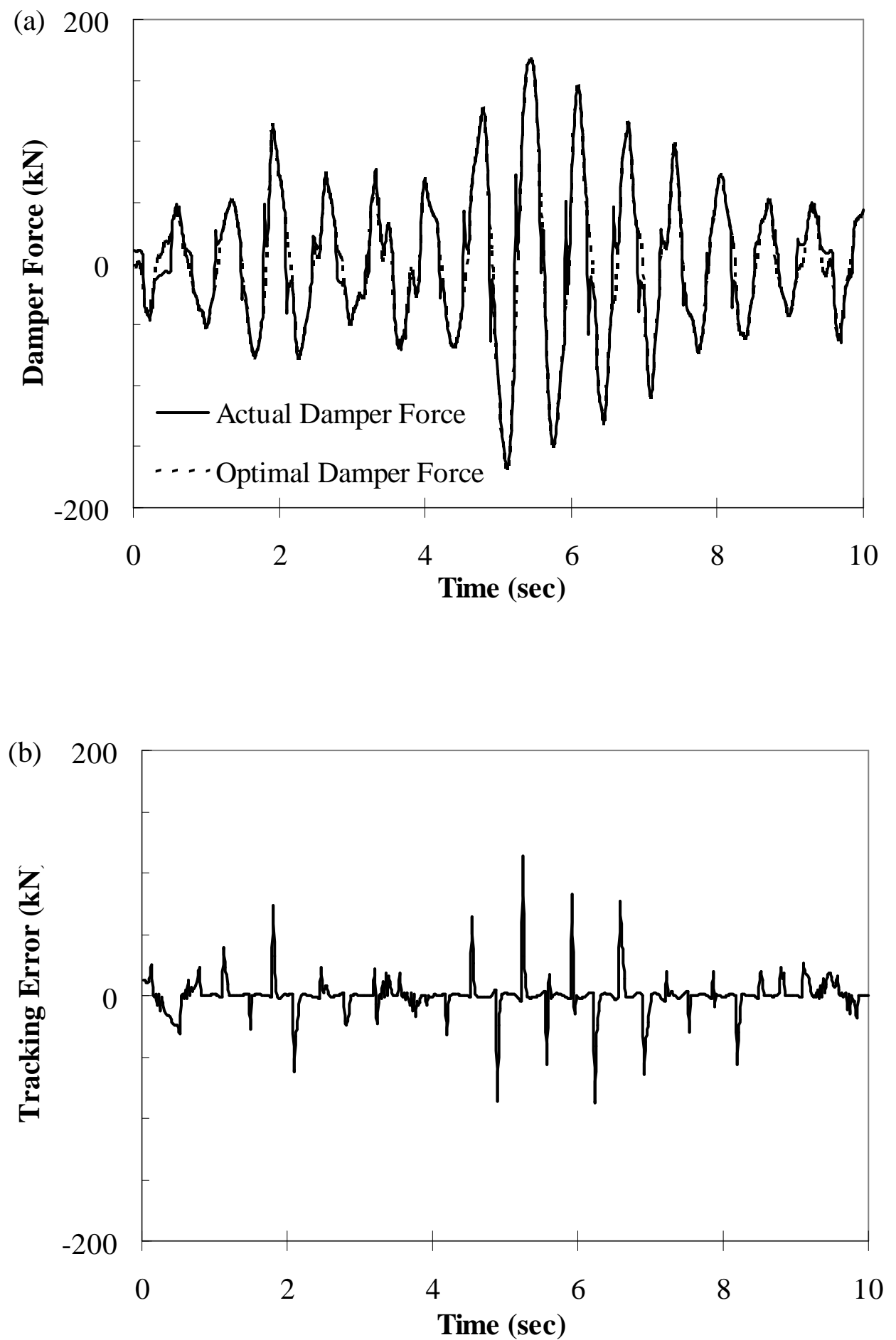

Figure 8. Bingham model - Simulation 1 -Damper Force Feedback (DFF) Algorithm: (a) Force Tracking; (b) Tracking error. 


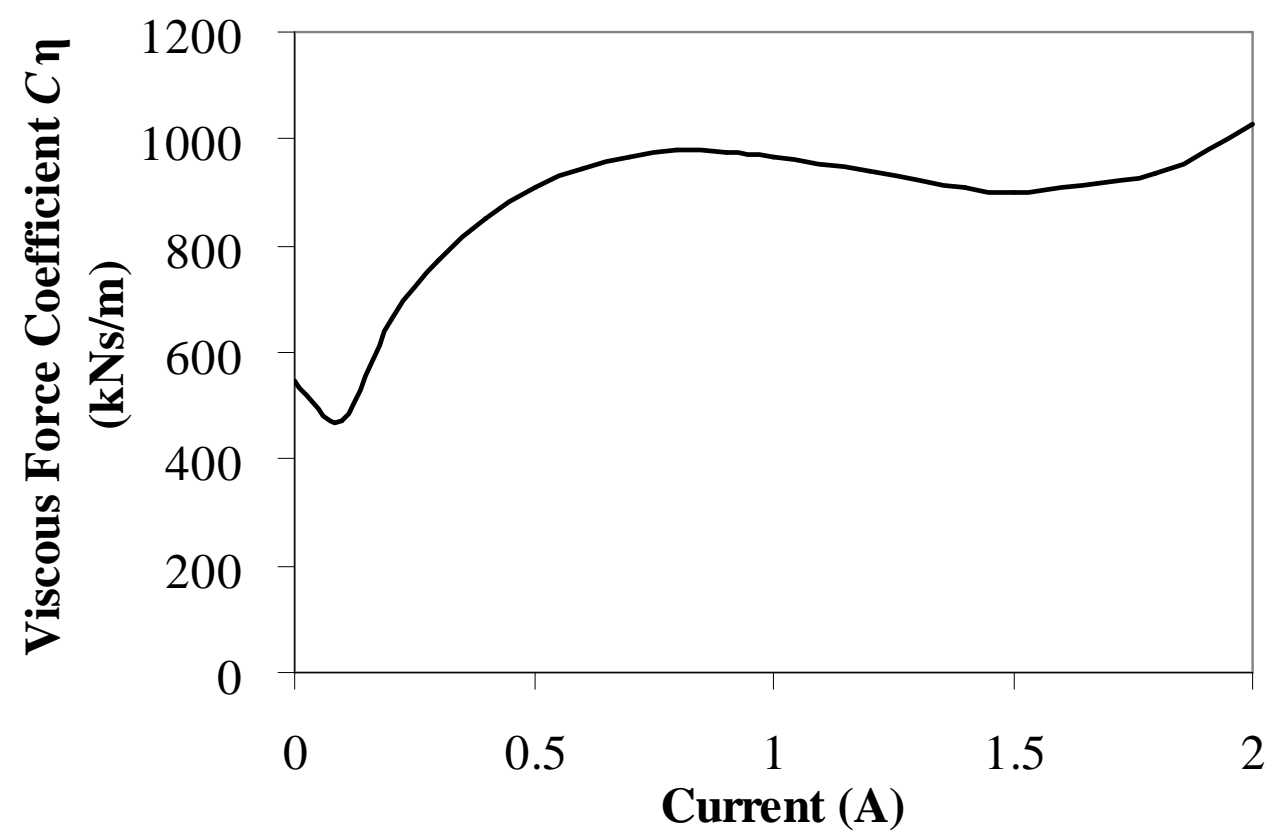

Figure 9. Bouc-Wen hysteresis model - Viscous Force Coefficient $C \eta$ versus Current $i$ (Large-scale MR damper) [11].

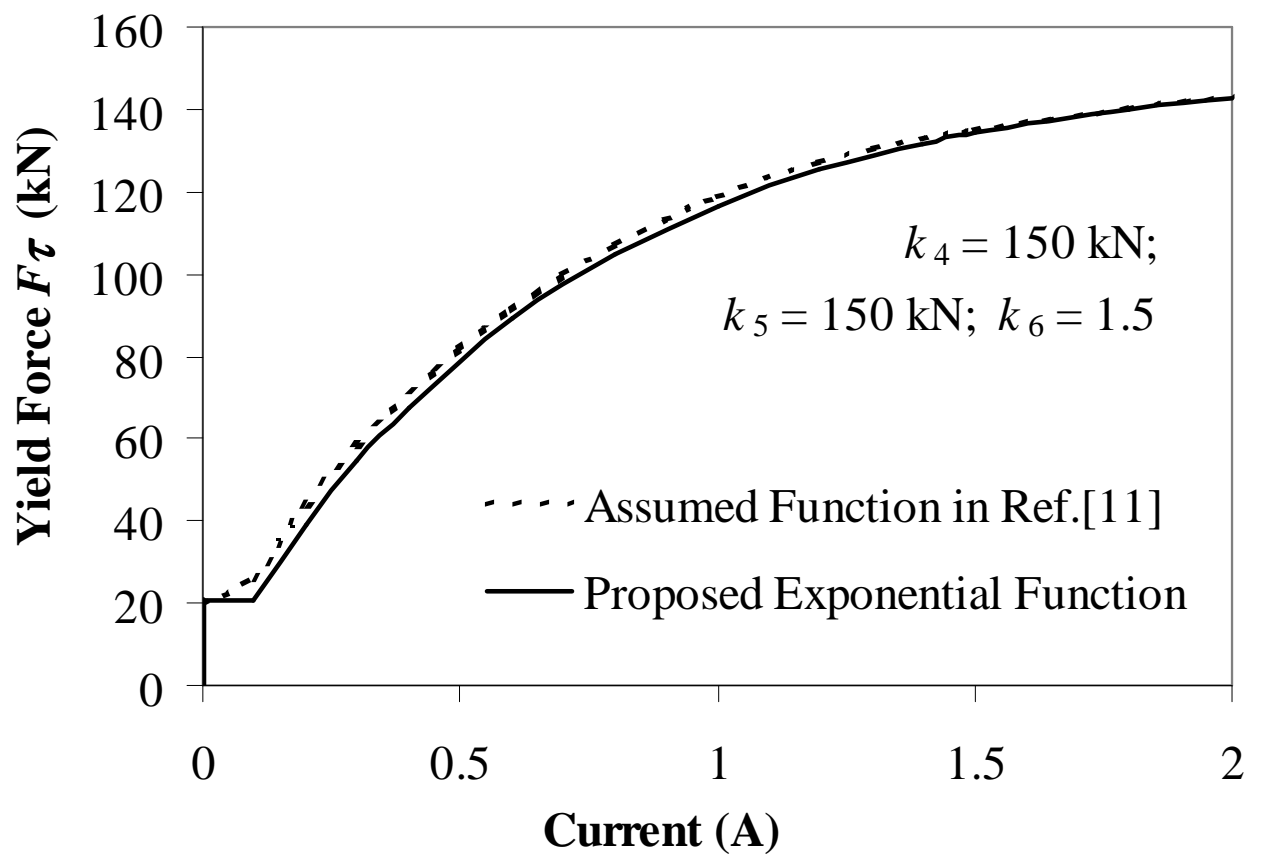

Figure 10. Bouc-Wen hysteresis model - Yield Force $F \tau$ versus Current $i$ (Large-scale MR damper) [11]. 

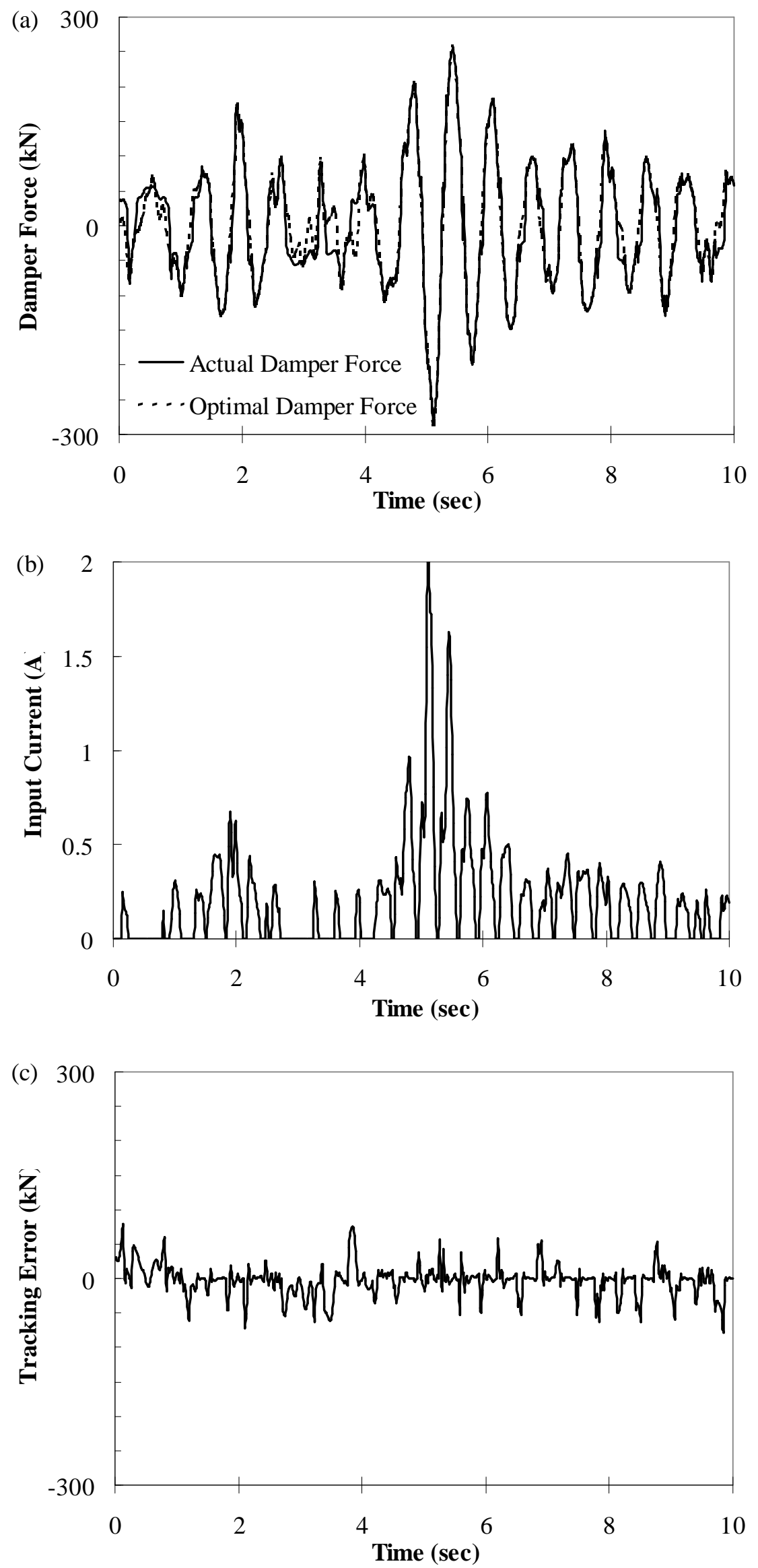

Figure 11. Bouc-Wen hysteresis model - Simulation 1: (a) Force tracking; (b) Input current variation; (c) Tracking error. 

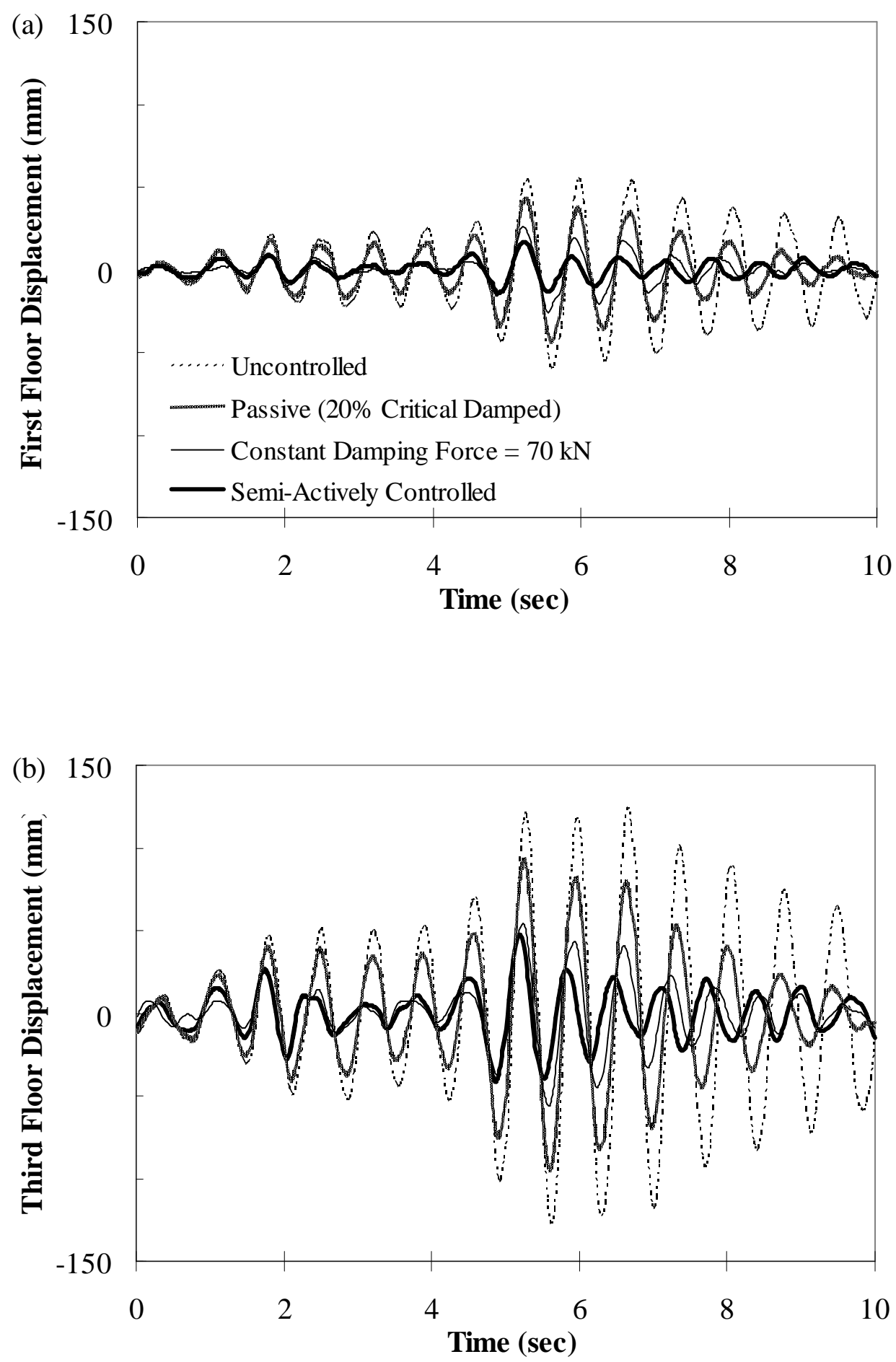

Figure 12. Bouc-Wen hysteresis model - Simuation 1 - Uncontrolled and semi-actively controlled displacement time histories: (a) First floor; (b) Third floor. 

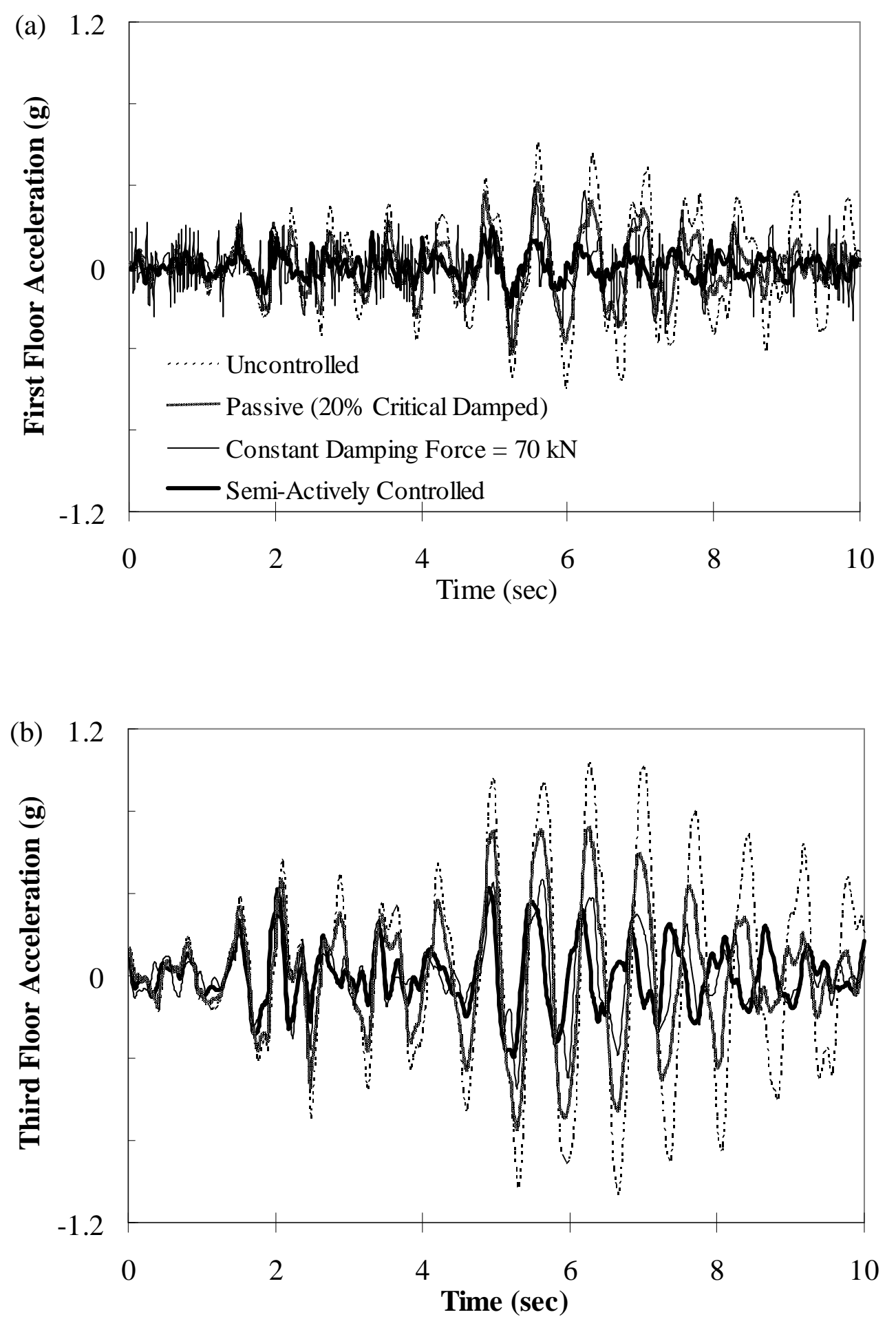

Figure 13. Bouc-Wen hysteresis model - Simulation 1 - Uncontrolled and semi-actively controlled acceleration time histories: (a) First floor; (b) Third floor. 

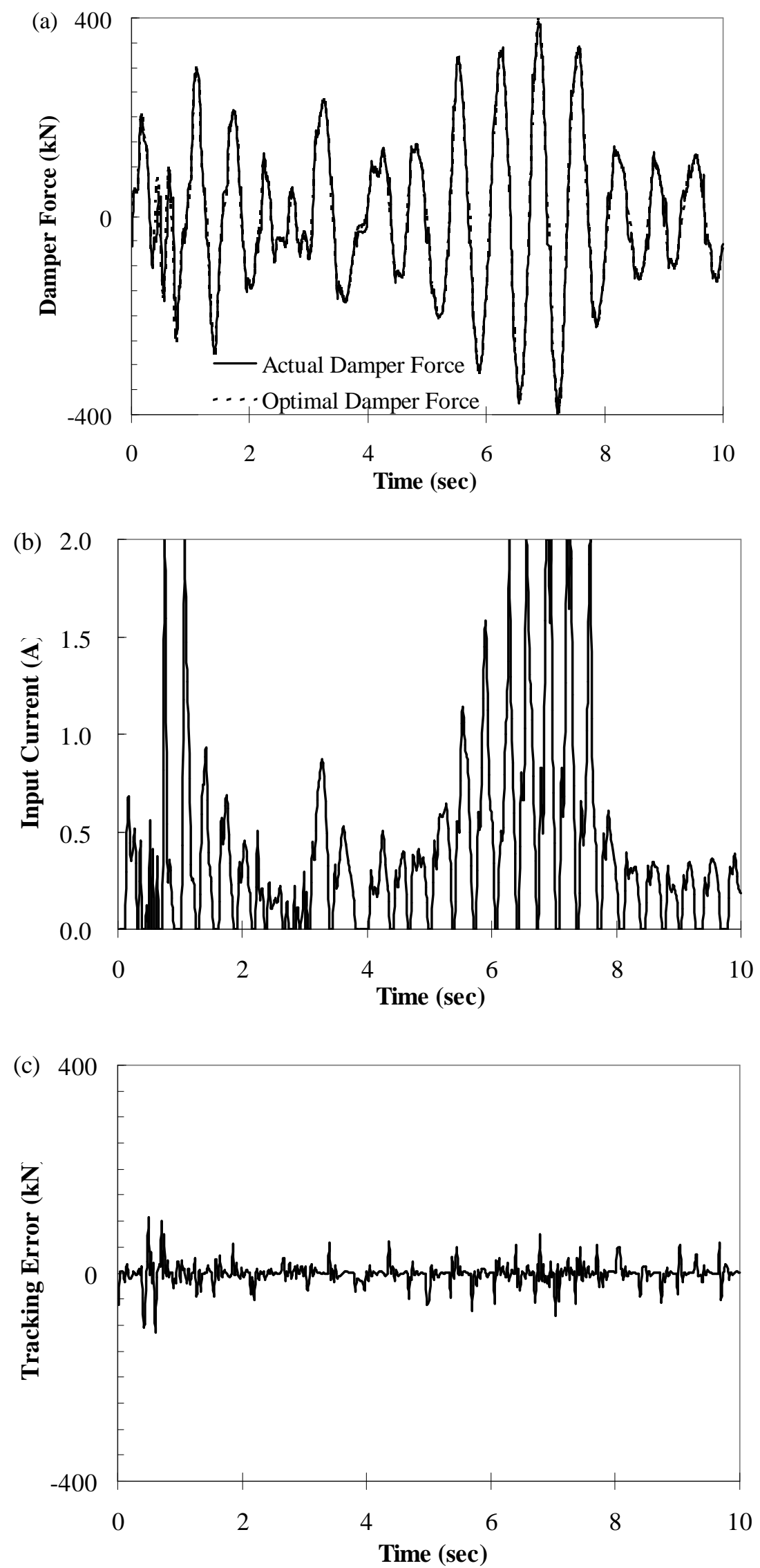

Figure 14. Bouc-Wen hysteresis model - Simulation 2: (a) Force tracking; (b) Input current variation; (c) Tracking error. 

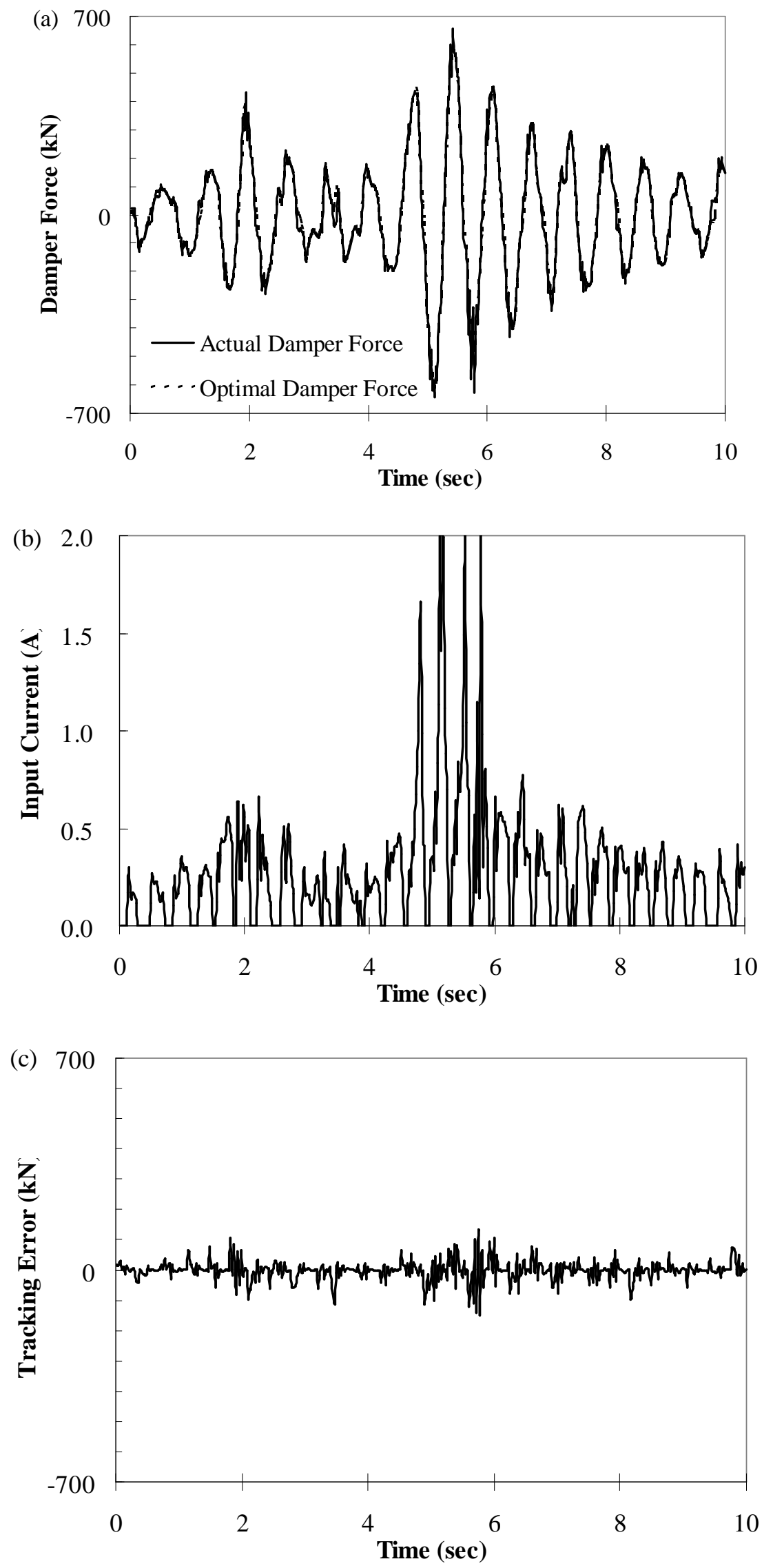

Figure 15. Bouc-Wen hysteresis model - Simulation 3: (a) Force tracking; (b) Input current variation; (c) Tracking error. 